\title{
La evolución demográfica de la ciudad de Soria entre 1700 y 1814
}

\author{
ANA ISABEL SANZ YAGÜE* \\ DEA por la UNED \\ The demographic Development in the town \\ of Soria, 1700-1814
}

\begin{abstract}
RESUMEN
El artículo analiza el movimiento de la población de la ciudad de Soria entre 1700 y 1814. Para ello se hace un seguimiento, bajo una perspectiva comparada, tanto de los censos y vecindarios, como de las principales variables demográficas extraídas de los libros parroquiales (natalidad, nupcialidad y mortalidad adulta). El estudio de la mortalidad parvular ha sido descartado por el momento, dada la importancia del subregistro a lo largo de todo el periodo.

Los resultados sitúan a este núcleo urbano entre aquellos que experimentaron una trayectoria más dramática, con una larga etapa recesiva entre 1724 y 1770 y una recuperación tardía en las tres últimas décadas del Setecientos. Una tendencia propiciada, en cualquier caso, por el protagonismo de la mortalidad de crisis hasta 1750 y una segunda mitad de siglo especialmente benévola.
\end{abstract}

PALABRAS CLAVE: Soria / evolución demográfica / crisis de mortalidad / siglo XVIII.

\section{ABSTRACT}

This paper analyzes the demographic development of Soria, in the North of Castile, for the period 1700 to 1814. Still untouched, both census and parish registers have been employed to carry out this objective and to examine short-run fluctuations of vital events from a comparative point of view. Nevertheless, the mortality of the people under 8 years of age has been discarded for the moment due to the under-reporting of infant deaths in the church books and therefore the bad quality of the data. The results are clearly worse than Castilian average. The number of baptisms decreases sharply for the large period 1724-1770 but the trend turns upwards in the last three decades of the Eighteenth Century. Mortality crisis remains significant until 1750 and plays a prominent role in the course of population. Amazingly, there is not any crisis between 1751 and 1803.

KEYWORDS:

Soria / Demographic development / Mortality crisis / $18^{\text {th }}$ Century.

\footnotetext{
* Doctoranda en el Programa de Tercer Ciclo "Sociedad, economía, instituciones, política y pensamiento político en la Edad Moderna" UNED. C/ Real, 12. 42112-Pinilla del Campo (Soria). e-mail: anaisy@telefonica.net
} 


\section{INTRODUCCIÓN}

La evolución demográfica de las poblaciones de la cuenca del Duero no se cuenta, sin duda, entre las más desconocidas, aunque es cierto que las variaciones sufridas a corto plazo y sus consecuencias no se han debatido a fondo. Además, el índice regional de bautismos castellano-leonés presentado por Enrique Llopis al VII Congreso de la Asociación de Demografía Histórica (Granada, 2004) todavía cuenta con la ausencia de cuatro de sus nueve provincias actuales (Salamanca, Soria, Valladolid y Zamora) ${ }^{1}$.

Desde el momento en que nos propusimos abordar una investigación sobre la ciudad de Soria en el siglo XVIII, la carencia de estudios demográficos locales constituyó un escollo, que debimos superar en primer lugar. Este artículo pretende describir los resultados más relevantes para el periodo 1700-1814, obtenidos tanto del estudio de los recuentos de población de esta centuria, como de los registros parroquiales, a través de los cuales se han analizado las principales variables demográficas: bautismos, matrimonios y defunciones.

No obstante, antes de abordar su análisis, debe superarse cualquier duda acerca del carácter urbano de Soria, dado que su población, en el siglo XVIII y en

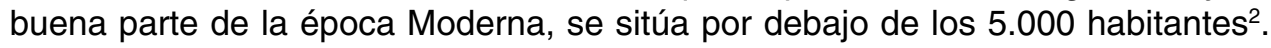
Así, su perfil socioprofesional, según muestra la averiguación catastral de 1752, puede ser suficiente para descartar cualquier parecido con una agrociudad, donde la población vinculada a las labores agrícolas es mayoritaria ${ }^{3}$. En esta fecha, el porcentaje de vecinos dedicados con exclusividad al sector primario no alcanza el $6 \%$, aunque si a esta cifra le añadimos los jornaleros (algo más del 14\%), más todos aquellos que además de realizar tareas agrícolas añaden a su rutina laboral actividades propias de otros sectores económicos, especialmente la arriería, la cifra asciende al $23,42 \% 4$. No obstante, tampoco es una ciudad mayoritariamente artesanal, como es el caso de Ávila o Segovia, sino que aquí el sector manufacturero y el terciario mantienen un equilibrio entre sí, apenas favorable al primero ${ }^{5}$.

1 LLOPIS AGELÁN, E.: «Índices regionales y nacional de bautismos, 1700-1849», VII Congreso de la Asociación de Demografía Histórica, Granada, 2004, <http://www.ugr.es/ adeh/comunicaciones/Llopis_ Agelan_E.pdf>

2 Los valores correspondientes a los vecindarios del siglo XVI, publicados por Enrique Díez, nos hacen pensar que la ciudad sólo se mantuvo por encima de los 5.000 habitantes en la segunda mitad del Quinientos. DÍEZ SANZ, E.: La Tierra de Soria. Un universo campesino en la Castilla oriental del siglo XVI, Siglo XXI de España Editores, Madrid, 1995, p. 36.

${ }^{3}$ Los datos ofrecidos aquí se han extraído de nuestra tesis doctoral, en proceso de elaboración, y son fruto de una revisión completa de los documentos catastrales de 1753 conservados en el Archivo Histórico Provincial de Soria (AHPSo, Sección Catastro, Cajas 9845 a 9850).

${ }_{4}$ Aunque cabría esperar, como en otras ciudades del interior castellano, un incremento de la proporción de activos vinculados al sector primario en el siglo XVIII, en Soria parece conservarse cierta estabilidad en el tiempo, ya que apenas difiere del porcentaje citado por Sofía Goyenechea para 1561, siempre y cuando se solvente la omisión de los jornaleros en este último padrón. GOYENECHEA PRADO, S.: «Aproximación a la estructura socio-profesional de la ciudad de Soria en el siglo XVI», Celtiberia, 90 (1996), pp. 273-302.

5 GARCÍA SANZ, Á.: Segovia 1753. Según las Respuestas Generales del Catastro de Ensenada, Tabapress (Col. Alcabala del Viento, n³4), Madrid, 1991. LLOPIS AGELÁN, E. y CUERVO, N.: «El mo- 


\section{FUENTES Y MÉTODO}

En esta investigación no se han descartado a priori ninguno de los recuentos de población del siglo XVIII, al tiempo que se han incluido en la elaboración de las series temporales de bautismos, matrimonios y defunciones todas las parroquias de la ciudad, con excepción de las dos únicas que presentaban serias lagunas en sus registros, San Esteban y Santa María del Poyo, las cuales, por otra parte, no representan más de un $15 \%$ del total urbano.

En principio, sólo el Vecindario General de España, elaborado en Soria hacia 1712, ha exigido cierta corrección, a partir de la cual es perfectamente aprovechable 6 . La primera medida adoptada con esta fuente ha debido orientarse a añadir los exentos (pobres y eclesiásticos) y a aplicar un factor de conversión a número de habitantes, para lo cual se ha extrapolado la situación observada en El libro de familias del Catastro de Ensenada, siguiendo la clásica metodología propuesta por Antonio Eiras Roel ${ }^{7}$. El volumen de población obtenido según este criterio implicaba un crecimiento anual acumulativo del 0,26\% entre 1712 y 1752 , lo cual no resulta irreal. Sí lo era la tasa bruta de bautizados, calculada con las series parroquiales como test de fiabilidad y superior al 46 por mil${ }^{8}$, inverosímil y distinta a las obtenidas para fechas posteriores ${ }^{9}$. En consecuencia, hemos optado por añadir una nueva rectificación a partir de la tasa más fiable, la de 1752 (41 por mil), por otra parte semejante a las observadas para el interior peninsular en regímenes de alta presión demográfica, lo que ha significado elevar la cifra inicial un 14,06\%.

Los datos relativos a 1752 proceden del libro de familias o de cabezas de casa y de la respuesta $39^{\mathrm{a}}$ del interrogatorio general, referida al clero secular, del Ca-

vimiento de la población en la provincia de Ávila, 1580-1864», VII Congreso de la Asociación de Demografía Histórica, Granada, Universidad, 2004, p. 10 < http://www.ugr.es/ adeh/comunicaciones/Llopis_ Cuervo.pdf>

6 Censo de Campoflorido. 1712. Vecindario General de España, tomo I, INE, Madrid, 1996.

7 EIRAS ROEL, A.: «Test de concordancia aplicado a la crítica de vecindarios fiscales de la época preestadística», Actas de las I Jornadas de metodología aplicada de las ciencias históricas. Metodología de la Historia Moderna. Economía y Demografía, Universidad, Santiago de Compostela, 1975, pp. 360386 , (p. 365). En Soria, en 1752, los pobres constituyen un 8,50\% del vecindario, si bien la población alojada en sus hogares se reduce al $5 \%$ del total de habitantes. Por otra parte, un $4,91 \%$ de los individuos reside en hogares cuyo cabeza de casa pertenece al clero secular, mientras el clero regular representa el $5,22 \%$ de los habitantes de la ciudad. En relación con el factor de conversión, hemos optado por el 4,21 por la razón siguiente. El libro de familias del Catastro constata un total de 824 hogares en el que residen 3.217 individuos. Esto significa que debería aplicarse el coeficiente de 3,91 habitantes por vecino, pero puesto que el vecindario de Campoflorido sigue computando el número, por otra parte indeterminado, de viudas por mitad, el índice multiplicador correcto debe elevarse a 4,21 habitantes, de aplicar las proporciones encontradas en 1752. En este año, las viudas representan el $14,2 \%$ de los vecinos seglares.

8 Para mitigar los contrastes interanuales de esta tasa, equiparable en las sociedades preindustriales a la de natalidad, se han utilizado series de bautismos correspondientes a las medias móviles de cinco años. Además, se ha utilizado como numerador el promedio de 9 años, en cuyo centro queda el año correspondiente a la averiguación fiscal.

9 Las tasas de natalidad superiores al 45 por mil son, en opinión de Wrigley, poco frecuentes, lo cual también puede deberse en coyunturas excepcionales a una anomalía en la estructura de edad. WRIGLEY, E.A.: Historia y población. Introducción a la demografía histórica, Guadarrama, Madrid, 1969, p. 62. 
tastro de Ensenada, por ser el recurso más fiable. El vecindario de 1759-1760 presenta errores importantes que obligan a prescindir de él. La mala calidad de este documento se apreció ya en el momento de su elaboración y sigue arrastrando un problema fundamental, que, en opinión de Concepción Camarero y Jesús Campos, radica en haber añadido en la columna correspondiente a los vecinos pecheros «los hijos y criados de éstos, mayores de dieciocho años» ${ }^{10}$.

Por otro lado, el desconocimiento que tenemos acerca del proceso de elaboración de los Censos de Aranda y Floridablanca es un inconveniente que nos obliga a trabajar tan solo con los resúmenes publicados por el INE ${ }^{11}$. Las tasas brutas de bautismos, obtenidas para estos dos hitos censales de 1768 y de 17861787 , no han resultado inicialmente sospechosas aunque su valor desciende al 39,6 por mil, situándose, por tanto, por debajo de la cifra de 1752. Esto significa, por otra parte, que, en el caso de Soria, al igual que se ha demostrado para otras poblaciones, no es oportuno aplicar al Censo de Floridablanca el incremento del $5 \%$, sugerido ya inicialmente por sus promotores ${ }^{12}$.

El manejo de los libros parroquiales ha seguido las directrices habituales del método agregativo. No obstante, el análisis de las series temporales, las primeras que vamos a tratar aquí, queda reducido a la natalidad (sería más correcto hablar de bautismos), la nupcialidad y la mortalidad adulta. La mortalidad parvular ha resultado defectuosa, incluso para las décadas finales, donde el hábito de registro parecía estar consolidado. Su explicación requiere un espacio amplio que excede las posibilidades de este artículo, por lo que preferimos tratarla con un carácter monográfico en otra ocasión.

Asimismo, se ha procedido a una detección básica de la mortalidad de crisis a través del recurso diseñado por los profesores Lorenzo Del Planta y Massimo Livi-Bacci, el cual se ha aplicado además a cada sexo por separado, con la intención de detectar situaciones de desequilibrio que pudieran afectar a la estructura poblacional en el corto y medio plazo ${ }^{13}$.

10 De la primera versión se deducía un crecimiento tan irreal que fue devuelto por la propia Junta del Buen Retiro para su corrección. Aun así, de los datos definitivos se desprende una tasa de crecimiento medio anual, para este periodo de ocho años, superior al 1\%, el cual sigue siendo inverosímil. CAMARERO, C. y CAMPOS, J.: «EI Vecindario de Ensenada para la Corona de Castilla. Estudio Preliminar», Vecindario de Ensenada 1759, Vol. I, Tabapress, Madrid 1991, p. XCI.

11 El Censo de Aranda terminó de elaborarse en Soria en los meses de octubre y noviembre de 1768 mientras los resúmenes o Estados del Censo de Floridablanca se cumplimentaron entre diciembre de 1786 y abril del año siguiente. Censo de Aranda, Tomo VI, INE, Madrid, 2003. Censo de 1787 «Floridablanca». Soria, INE, Madrid, 1988.

12 Una situación semejante a la observada para Castilla-La Mancha. David-Sven Reher no considera apropiado este incremento para Cuenca. Una posición similar a la adoptada por Manuel Martín Galán, para quien cualquier incremento debería ser, en cualquier caso, inferior al 5\%. MARTíN GALÁN, M.: «La población de Madrid y Castilla-La Mancha según el Censo de Floridablanca», La Población Española en 1787. II Centenario del Censo de Floridablanca, INE, Madrid, 1992 pp. 157-192, p. 164.

13 PÉREZ MOREDA, V.: Las crisis de mortalidad en la España interior (siglos XVI-XIX), Siglo XXI editores, Madrid, 1980, pp. 100-106 y 113-119. 
Finalmente, dedicaremos un último apartado a valorar la trayectoria cuantitativa de la población, mostrada por los censos y vecindarios, que al mismo tiempo podrán ser interpretados bajo la luz crítica de la información parroquial.

\section{LA EVOLUCIÓN DEMOGRÁFICA A PARTIR DE LOS REGISTROS PARROQUIALES}

A grandes rasgos, la serie de bautismos del periodo 1700-1814 presenta cuatro etapas de dimensiones cronológicas desiguales dentro de una tendencia marcada por el estancamiento (ver APÉNDICE I, GRÁFICO 1). La primera, ligeramente alcista, por cuanto se logra un incremento del $6 \%$ en el promedio de bautizados, ocupa prácticamente el primer cuarto de la centuria. La segunda responde a un largo proceso contractivo que finaliza en torno a 1770 con una caída notable en el número de bautismos, que puede alcanzar entre el 21,7 y el $24,3 \%$, según se consideren o no los expósitos (de los cuales no todos proceden de la ciudad). Tras ella, en los años setenta se inicia una etapa positiva que se prolonga hasta el final de la centuria, donde, concretamente en su última década, se logra recuperar un nivel de bautismos semejante o apenas superior al de los años veinte. El siglo XIX, por el contrario, abre las puertas a una trayectoria negativa en sus primeros años pero de evolución incierta, que nuestro estudio, interrumpido en 1814, no nos permite más que entrever.

TABLA 1: Porcentajes y tasas de variación aproximados

\begin{tabular}{ccccccc}
\hline & \multicolumn{2}{c}{ Con expósitos } & & \multicolumn{2}{c}{ Sin expósitos } \\
\cline { 2 - 3 } \cline { 5 - 6 } Periodo & $\begin{array}{c}\text { Variación } \\
\text { porcentual }\end{array}$ & $\begin{array}{c}\text { Tasa de } \\
\text { variación }\end{array}$ & Periodo & & $\begin{array}{c}\text { Variación } \\
\text { porcentual }\end{array}$ & $\begin{array}{c}\text { Tasa de } \\
\text { variación }\end{array}$ \\
\hline $1700 / 08-1720 / 28$ & 6,29 & 0,30 & $1700 / 08-1720 / 28$ & 6,67 & 0,32 \\
$1706 / 14-1720 / 28$ & 12,59 & 0,85 & $1706 / 14-1720 / 28$ & 11,63 & 0,78 \\
$1720 / 28-1729 / 37$ & $-18,42$ & $-2,23$ & $1720 / 28-1729 / 37$ & $-20,14$ & $-2,46$ \\
$1720 / 28-1766 / 74$ & $-21,71$ & $-0,53$ & $1720 / 28-1766 / 74$ & $-24,31$ & $-0,60$ \\
$1729 / 37-1743 / 51$ & 13,71 & 0,92 & $1729 / 37-1743 / 51$ & 12,17 & 0,82 \\
$1729 / 37-1766 / 74$ & $-4,03$ & $-0,11$ & $1729 / 37-1766 / 74$ & $-5,22$ & $-0,14$ \\
$1743 / 51-1766 / 74$ & $-15,60$ & $-0,73$ & $1743 / 51-1766 / 74$ & $-15,50$ & $-0,72$ \\
$1766 / 74-1790 / 98$ & 29,41 & 1,08 & $1766 / 74-1790 / 98$ & 28,44 & 1,04 \\
$1790 / 98-1806 / 14$ & $-7,14$ & $-0,46$ & $1790 / 98-1806 / 14$ & $-15,00$ & $-1,01$ \\
\hline
\end{tabular}

Fuente: Elaboración propia a partir de los libros parroquiales de bautismos.

Dentro de este marco general, interesa profundizar en las fluctuaciones más significativas del corto plazo (GRÁFICO 1, TABLA 1). Así, la primera etapa, a pesar de que finaliza con un balance positivo, sufre un profundo revés entre 1705-1710, tras el cual se sucede una rápida respuesta que podría cifrarse en una tasa de crecimiento medio acumulativo del 0,78 ó $0,85 \%$ (sin y con expósitos). 
Del mismo modo, el largo periodo de declive que se extiende entre 1724 y 1770 , no responde a un proceso regular de decrecimiento sino que está sometido a fuertes variaciones. En la ciudad de Soria, los años treinta son globalmente negativos, pero hay que distinguir entre una primera mitad regresiva, con un fuerte descenso entre los años 1728 y 1730, y una recuperación posterior que perdurará hasta el año 1745. En este momento, aunque no se alcance el máximo de bautismos registrado en las décadas precedentes, la reacción sucesiva a la crisis es semejante e incluso levemente más intensa que la experimentada a comienzos de siglo. No obstante, la tendencia se interrumpe de nuevo y el decrecimiento vuelve a ser la tónica dominante hasta el comienzo de los años setenta, con alguna excepción puntual (años 1759 y 1762). Es precisamente entre 1768 y 1773 cuando se alcanza el momento más crítico para la natalidad.

Tras esta media centuria contractiva, las tres últimas décadas manifiestan un comportamiento demográfico distinto, donde se vive una fase de crecimiento más sostenido y se alcanzan los valores máximos del siglo (años 1793 y 1798). De hecho, entre 1766-1774 y 1790-1798 se logra aumentar en un $28,4-29,4 \%$ el número de bautismos, aunque esta ganancia se vea de nuevo interrumpida temporalmente en los primeros años del siglo XIX. En efecto, el quinquenio de 1799-1804 es profundamente negativo, aunque ya hacia 1806 se vuelven a registrar valores semejantes al de los años ochenta del Setecientos. El balance final del periodo 1790/98-1806/14 es, sin duda, negativo, aunque la llegada masiva de expósitos a la casa cuna de la ciudad atenúa de un modo significativo la caída. De hecho, los bautismos de niños residentes dentro de una unidad familiar llegan a descender un $15 \%$ tal y como se refleja en la TABLA 1.

El conjunto de fluctuaciones observadas en esta serie de bautismos, debe guardar una correspondencia lógica con la evolución de variables demográficas tan significativas como la mortalidad y, en concreto, la mortalidad de crisis. Las defunciones ordinarias de adultos han constituido uno de los parámetros demográficos más estables de las sociedades preindustriales, por lo que requieren poca atención. En Soria, esta regularidad debe enmarcarse dentro de una leve tendencia decreciente a lo largo del siglo XVIII (ver APÉNDICE I, GRÁFICO 2). Pero, con todo, lo que aquí nos interesa es distinguir las situaciones excepcionales de sobremortalidad.

En lo que respecta a la población adulta, son tres los momentos donde la mortalidad de crisis adquiere una significación especial (GRÁFICO 2, TABLA 2). EI primero de ellos corresponde al año 1707, donde las defunciones sobrepasan en un $163,4 \%$ los valores ordinarios, destacando especialmente la acusada mortalidad masculina. No obstante, deberíamos encuadrar este hecho en un periodo más amplio de inestabilidad demográfica, iniciado en 1706 y finalizado en 1710, con una leve sobremortalidad (índice 79,27), en este caso más volcada sobre el sexo femenino. La segunda crisis, de dimensiones parecidas a la de 1707 (índice 154,04), acontece en 1750, aunque está precedida por un leve incremento de la mortalidad 
masculina en 1749. Ninguna de ellas alcanza las dimensiones de la mortandad sufrida a comienzos del siglo XIX (índice 217,46), que asimismo incide con más crudeza sobre la población femenina.

\section{TABLA 2 : Cronología y significación de las crisis de mortalidad} (método de L. del Planta y M. Livi-Bacci)

\begin{tabular}{cccc}
\hline & \multicolumn{3}{c}{ Población adulta } \\
\cline { 2 - 4 } Periodo & Total & Varones & Mujeres \\
\hline 1707 & 163,40 & 199,14 & 124,11 \\
1710 & 79,27 & 59,91 & 82,26 \\
1729 & 72,62 & 73,26 & 76,47 \\
1742 & 41,91 & 54,85 & 30,05 \\
1749 & 46,98 & 55,55 & 38,61 \\
\hline 1750 & 154,04 & 113,88 & 180,00 \\
1782 & 48,03 & 59,28 & 30,23 \\
1789 & 56,55 & 19,62 & 72,99 \\
\hline 1803 & 75,97 & 47,57 & 105,65 \\
1804 & 217,46 & 174,07 & 264,67 \\
\hline
\end{tabular}

Fuente: Elaboración propia.

El resto de las crisis detectadas tienen una significación menor, al tiempo que se concentran preferentemente en la primera mitad del Setecientos. Así, tras las dificultades vividas entre 1706-1710, el año 1729 vuelve a conocer un nuevo episodio donde la mortalidad adulta se eleva en un $72,62 \%$ respecto de las cifras ordinarias. Es la única, además, que presenta una afectación por sexos más equilibrada, dentro de una tendencia marcada por la menor resistencia femenina. Los años cuarenta no constituyen globalmente un periodo de sobremortalidad adulta, aunque se aprecia un ligero incremento en la población masculina en los años 1742 y 1749.

Más allá de la fuerte crisis de 1750, puede decirse que la segunda mitad del siglo XVIII es especialmente benévola, ya que, si bien puede apreciarse en el GRÁFICO 2 una elevación de las defunciones tanto en los años sesenta, marcados por las crisis de subsistencias ${ }^{14}$, como durante el comienzo de los años setenta, especialmente negativo en todo el ámbito europeo ${ }^{15}$, ninguno de estos momentos críticos ha acarreado una situación de sobremotalidad. Del mismo modo, y aunque no vamos a abordar aquí ni la casuística ni la distribución estacional de cada una de estas crisis por razones de espacio, es evidente que las epidemias de paludismo,

14 PÉREZ MOREDA, V.: Las crisis..., p. 363.

15 POST, J. D.: «The Mortality Crisis of the Early 1770s and European Demographic Trends», Journal of Interdisciplinary History, vol. 21, n 1 (Summer, 1990), pp. 29-62. 
propagadas por el interior peninsular a partir de 1783 no llegan a alcanzar en Soria el carácter de mortalidad de crisis $^{16}$. El único momento destacable aunque no tenga relevancia cuantitativa es la elevación de las defunciones de mujeres en 1789 (índice global 56,55; masculino 19,62; femenino; 72,99), año vinculado, por otra parte, a problemas de desabastecimiento en el ámbito peninsular ${ }^{17}$, y la leve sobremortalidad masculina de 1782, que no llega a marcar una verdadera crisis dentro del conjunto poblacional ${ }^{18}$.

Conocida ya la evolución de los bautismos y de la mortalidad adulta, resta por describir el comportamiento de la nupcialidad, uno de los factores especialmente influyentes en el tiempo de recuperación del nivel estable por el que pasan las diversas poblaciones tras una situación de crisis $^{19}$. La trayectoria descrita por el GRÁFICO 3 nos muestra una situación bastante regular donde se alternan breves episodios alcistas, que habrá que observar si están asociados a crisis de mortalidad, seguidos de fases más largas dominadas por una tendencia ligeramente negativa. Situaciones de este tipo podríamos contabilizar hasta diez a lo largo del periodo estudiado. Sin embargo, interesa centrar la atención en los cuatro episodios verdaderamente atípicos.

El primero de ellos, comprendido entre 1708 y 1714, constituye uno de los periodos más prolongados en los que se mantienen unos valores de nupcialidad comparativamente altos. Una situación que, sin duda, responde al periodo de inestabilidad demográfica comprendido entre 1706 y 1710, en el que se inserta la principal sobremortalidad del siglo XVIII, la de 1707 . El bienio de $1742-1743$ representa un nuevo episodio excepcional, aunque menos lógico desde una perspectiva interna, por no estar asociado con crisis de mortalidad inmediatas. No obstante, sus valores son significativos ya que el número anual de matrimonios de este breve lapso supera en más de un $30 \%$ la media de los años inmediatos, convirtiendo así a la década de los cuarenta en la más favorable desde el punto de vista de la nupcialidad.

El siglo XIX acoge otras dos coyunturas atípicas y de signo opuesto. Por una parte, en los años sucesivos a la fuerte crisis de 1804, el trienio de 1805-1807, el número de enlaces crece considerablemente en unos márgenes similares a los de 1742-1743 (63-65 bodas/año). Por otra, la nupcialidad cae en picado en los años de 1810-1812, llegando a alcanzarse aquí el mínimo del periodo (10 bodas/año), en un contexto más que comprensible teniendo en cuenta el conflicto bélico que afecta a la península.

Hasta aquí ha llegado la descripción individual de las tres variables demográficas. En síntesis, la ciudad pasa por un primer momento alcista en las dos prime-

16 PÉREZ MOREDA, V.: Las crisis...., pp. 336-338.

17 Ibídem, p. 368.

18 Esta cronología coincide con la ofrecida por Vicente Pérez Moreda para las crisis de 1780-82 del interior castellano. Ibídem, p. 355.

19 LE BRAS, H.: «Retour d'une population á l'état stable après une "catastrophe"», Population (French edition), 24 année, 5 (sept-oct. 1969) pp. 861-896, especialmente pp. 888-890. 
ras décadas del siglo XVIII, afectado por un periodo de sobremortalidad de consecuencias relevantes para el resto de la centuria; una larga etapa contractiva que dura prácticamente cincuenta años, bajo los cuales se registra una crisis demográfica considerable a mediados de siglo y episodios más leves pero circunscritos a la primera mitad del mismo; $y$, finalmente, un periodo de recuperación en las tres últimas décadas del Setecientos, interrumpido por una nueva coyuntura inestable, donde la cruenta mortandad de 1804 tiene un protagonismo especial. ¿En qué medida se asemeja o difiere esta situación a la del conjunto del interior peninsular?

\section{LA EVOLUCIÓN DEMOGRÁFICA DE SORIA EN EL MARCO DE UNA HISTORIA COMPARADA.}

A partir de los índices elaborados por Enrique Llopis, podemos observar cómo el movimiento de la población castellano-leonesa y el relativo al conjunto de la España interior y la Andalucía occidental difieren poco en el periodo estudiado aquí (GRÁFICO 5). Dentro de este contexto, la ciudad de Soria se ajusta a un perfil semejante en la primera mitad del siglo XVIII, aunque las fluctuaciones interdecenales de su serie de bautismos son más extremas: sufre con más intensidad las fases contractivas (segunda y cuarta décadas), no tiene tanta capacidad de recuperación en los años veinte, pero sí logra un crecimiento proporcionalmente mayor en los cuarenta.

Por el contrario, Soria inicia la segunda mitad del siglo con un comportamiento totalmente opuesto al que se está viviendo en buena parte del interior peninsular: decrece en una de las décadas más expansivas de la centuria, los años cincuenta, y no toca fondo hasta el inicio de los años setenta, donde la inversión de la tendencia nos debe sugerir, por otra parte, un comienzo más precoz de la fase alcista dominante hasta el final de la centuria.

Una situación semejante e incluso más dramática puede observarse en la ciudad de Ávila, estudiada por Enrique Llopis y Noemí Cuervo, la cual carece del crecimiento de los años ochenta y no logra siquiera alcanzar el máximo de bautismos de las primeras décadas del siglo (ver APÉNDICE I, GRÁFICO 6) ${ }^{20}$. Ahora bien, no es fácil saber si la tendencia descrita para estas dos ciudades es la tónica dominante en el ámbito urbano regional. Según Fernando Ortega Barriuso, la ciudad de Burgos no parece entrar en una clara recuperación hasta el reinado de Carlos III $^{21}$, mientras el incremento en el número de bautismos de Palencia entre

20 «[...] la auténtica recuperación de este núcleo no se iniciaría hasta después de 1835 y, además, tampoco destacaría por su vitalidad. De modo que la ciudad de Ávila no recobraría la población de los años setenta del siglo XVI hasta bastante después de 1865» LLOPIS AGELÁN, E. y CUERVO, N.: «EI movimiento...", p. 17.

21 CIBEIRA ARIAS, E.: «La población en la provincia de Burgos, 1700-1850», VII Congreso de la Asociación de Demografía Histórica, Universidad, Granada, 2004, pp. 11-12. <http://www.ugr.es/ adeh/ comunicaciones/Cibeira_E.pdf> 
1710-1709 y 1780-1799, aunque débil (3,4\%), puede sugerirnos un comportamiento más dinámico, lo mismo que ocurre en Valladolid ${ }^{22}$. Por su parte, el estudio aportado por Laureano Rubio para León nos presenta una ciudad dominada por unos parámetros bien distintos. Además de recuperar a comienzos del siglo XVIII el nivel de bautismos alcanzado en la década de 1600-1609, la ciudad crece hasta el final de los años sesenta (aunque con una etapa regresiva entre 1730-1749), tiene un amplio crecimiento en los cincuenta y sufre un importante retroceso entre 1765 y 1785, compensado con el fuerte incremento de la última década ${ }^{23}$.

En cualquier caso, la evolución demográfica de ciudades como Soria o Ávila contrasta con la del ámbito rural castellano, que a lo largo del Setecientos crece, como es sabido, a un ritmo superior al de los núcleos urbanos (GRÁFICO 6). La diferencia radica no sólo en el mayor crecimiento de la zona rural durante la primera mitad, sino especialmente en el comportamiento de ambos espacios en los años cincuenta. En contrapartida, cabe señalar que los últimos treinta años, son mucho más dinámicos en lo que respecta a Soria, dado el estancamiento de las poblaciones rurales a partir de las crisis agrarias de los años sesenta, como se ha demostrado tanto en Segovia como en Burgos ${ }^{24}$.

La profunda divergencia observada entre los ámbitos rural y urbano de la cuenca del Duero para el periodo 1720-1755 vuelve a repetirse frente al horizonte urbano más próximo, que interesa y es posible comparar. En este sentido, tanto Logroño (podría incluso hablarse del territorio riojano) como Tarazona (reino de Aragón) logran superar la crisis de comienzos de siglo experimentando una evolución muy positiva hasta aproximadamente los años sesenta, aunque la primera de ellas, al igual que sucedía en las poblaciones rurales de la submeseta norte, sufrirá un notorio estancamiento entre 1760 y 1790 (ver APÉNDICE I, GRÁFICO 7) ${ }^{25}$.

Las diferencias entre estos últimos núcleos urbanos se mitigan a la hora de tratar la mortalidad de crisis adulta (GRÁFICO 8), aunque la sincronía observada entre Soria y Tarazona no abarca a Logroño, especialmente si nos centramos en el

22 «El número de bautismos en Valladolid sólo aumentó en un 15,6 por 100 entre 1700-1709 y 1780 1799. Menos aún creció el número de bautizados en Palencia entre las mismas fechas: en un 3,4 por 100 exactamente". En cualquier caso, son incrementos superiores al de Soria, que apenas crece un $0,48 \%$ en este mismo periodo y, por supuesto, mayores que el de Ávila, donde se advierte un retroceso del $-9,36 \%$. GARCIA SANZ, A.: «El interior peninsular en el siglo XVIII: un crecimiento moderado y tradicional», en Roberto Fernández (ed.), España en el siglo XVIII. Homenaje a Pierre Vilar, Crítica, BarceIona, 1985, pp. 630-680, p. 639.

${ }^{23}$ RUBIO PÉREZ, L. M.: «Introducción», León, 1751. Según las Respuestas Generales del Catastro de Ensenada, Tabapress (Col. Alcabala del Viento, n 45), Madrid, 1993 pp. 56-63.

${ }^{24}$ CIBEIRA ARIAS, E.: «La población...»; y GARCíA SANZ, Á.: Desarrollo y crisis del Antiguo Régimen en Castilla la Vieja. Economía y Sociedad en tierras de Segovia de 1500 a 1814, Akal, Madrid, 1986, pp. 50-74.

${ }_{25}$ LÁZARO RUIZ, M.: La población de la ciudad de Logroño, Gobierno de la Rioja e Instituto de Estudios Riojanos, Logroño, 1994; GURRÍA GARCíA, P. A.: La población de La Rioja durante el Antiguo Régimen demográfico, 1600-1900, Gobierno de La Rioja-Instituto de Estudios Riojanos, Logroño, 2004; y VALLEJO ZAMORA, J.: La población de Tarazona en el siglo XVIII: estudio demográfico, Institución Fernando el Católico, Zaragoza, 1987. 
segundo cuarto de la centuria. Si, por el contrario, observamos el comportamiento de la segunda mitad del siglo, en todas ellas se aprecia un notable avance en el control de la mortalidad durante los años ochenta, destacando especialmente los bajos valores de Soria. Esta situación es significativa por cuanto nos permite englobar esta ciudad junto a las regiones del norte peninsular (Navarra, territorio riojano en su conjunto, provincia de Burgos...), que escapan a las epidemias de paludismo sufridas con intensidad en la zona centro (GRÁFICO 9$)^{26}$.

Esta evolución desigual constituye con toda probabilidad una clara diferencia entre los dos núcleos urbanos comparados al principio, Soria y Ávila, ya que la tendencia regresiva de los años ochenta en esta última bien podría estar motivada por la mayor incidencia de esta infección. No obstante, no puede descartarse la presencia de sobremortalidad por paludismo dentro de la provincia de Soria o en su mitad sur, sobre todo si tenemos en cuenta la información proporcionada por Vicente Pérez Moreda ${ }^{27}$. La intervención de la Sociedad Económica de Amigos del País puede ser una de las razones que permitan explicar su evolución favorable en estos momentos ${ }^{28}$.

Con todo lo descrito hasta ahora, ¿cómo puede interpretarse la evolución demográfica de la ciudad de Soria? En nuestra opinión, pueden destacarse dos situaciones sobre las que debería trabajarse con más profundidad en un futuro. La primera de ellas abarca la prolongada regresión experimentada entre los años veinte y el final de los sesenta. Un periodo en que, por una parte, las fluctuaciones comunes a un amplio territorio del interior peninsular son aquí más extremas y, por otra, no se logra la típica expansión de los años cincuenta. La segunda comprende la recuperación de las tres últimas décadas del siglo (ya desde el comienzo de los años setenta, lo cual resulta bastante temprano dentro del territorio castellano comparado aquí) y la reducción de la mortalidad adulta, que le asemeja más a los territorios contiguos del norte que al centro peninsular.

En cualquier caso, y aunque todavía nuestro nivel de investigación no permite aventurar ninguna explicación coherente al respecto, creemos que debe darse una mayor importancia al momento de inestabilidad, no sólo demográfica, de 17061710 y sus consecuencias posteriores. Sin que podamos establecer ponderaciones

${ }^{26}$ CIBEIRA ARIAS, E.: «La población...», p. 38; GURRÍA GARCÍA, P. A.: La población..., p. 122; MIKELARENA PEÑA, F.: La evolución de la población, regímenes demográficos y estructuras familiares en la Navarra tradicional, 1553-1900, tesis doctoral inédita, UNED, 1992, p. 260; y PÉREZ MOREDA, V.: Las crisis..., pp. 336-350.

27 «Las respuestas a Tomás López de las localidades de Soria, Segovia y Valladolid muestran, si bien no tan claramente como las de Castilla la Nueva y Extremadura, la demoledora acción del paludismo unos años antes», en PÉREZ MOREDA, V.: Las crisis..., p. 339.

28 «En 1786 la Sociedad tuvo una gran importancia en la curación de la epidemia de tercianas. Por su mediación fueron enviadas desde Madrid 4 arrobas de quina para aplicarla a los enfermos. En traerla, molerla y distribuirla a los distintos arciprestazgos, empleó 238 rs. 20 mrs. Mucho más representativo del espíritu abierto de los Amigos del País para acoger toda reforma o invento que pudiera ser útil es la inversión de 1.170 rs. en una «máquina eléctrica» para curar las enfermedades de tercianas», en RUPÉREZ ALMAJANO, M. N.: La Sociedad Económica de Amigos del País de Soria (1777-1809), Diputación Provincial, Soria, 1987, pp. 164-165. 
serias, cabe achacarle a la sobremortalidad de este periodo una parte de responsabilidad en la difícil trayectoria posterior, ya que, si bien las tres variables parecen recuperar su nivel anterior hacia 1715 (GRÁFICO 4), una mortalidad que afecte con más intensidad a los jóvenes, más el vacío provocado por quienes ni siquiera llegaron a nacer durante la crisis, justifica un menor número de bautismos en las décadas sucesivas y un periodo de recuperación más prolongado, sobre todo en ausencia de movimientos migratorios favorables ${ }^{29}$. De hecho, ciudades como Logroño y Tarazona crecen en su primera mitad a partir de una significativa inmigración ${ }^{30}$.

No sabemos aún cual fue el comportamiento de esta última variable en Soria, pero el hecho de que la crisis de 1750 no provocase una reacción lógica en términos de nupcialidad y natalidad nos lleva a intuir que su pirámide poblacional se encuentra seriamente desequilibrada (GRÁFICO 4).

\section{EVOLUCIÓN CUANTITATIVA DE LA POBLACIÓN A PARTIR DE LOS CENSOS Y VECINDARIOS}

Nada de lo expuesto anteriormente contradice los datos procedentes de los recuentos de población del siglo XVIII, aunque a partir de este tipo de fuentes sólo podamos adquirir una impresión muy general del panorama demográfico y, lo que es más importante, una idea bastante aproximada de las dimensiones de la ciudad. Según los datos originales, entre 1712 y 1768, la ciudad experimenta una pérdida de población moderada, por cuanto pasa de tener casi 3.700 habitantes en 1712 a un total de poco más de 3.500 en 1768. La recuperación entre 1768 y 1787 queda igualmente constatada, teniendo en cuenta que en este último año se sobrepasan ligeramente los 3.800 habitantes, aunque es difícil pensar en un volumen superior a los 4.000 para el final de la centuria.

TABLA 3: Evolución cuantitativa de la población

\begin{tabular}{ccccc}
\hline & $\mathbf{1 7 1 2}$ & $\mathbf{1 7 5 2}$ & $\mathbf{1 7 6 8}$ & $\mathbf{1 7 8 6 - 8 7}$ \\
\hline Habitantes & 3.683 & 3.580 & 3.557 & 3.814 \\
\hline $\begin{array}{c}\mathbf{N}^{\circ} \text { índices } \\
(\mathbf{1 5 2 7 = 1 0 0 )}\end{array}$ & 100,0 & 97,2 & 96,6 & 103,6 \\
\hline
\end{tabular}

Fuente: Libro de familias del catastro de Ensenada para 1752; INE para los censos y vecindarios restantes.

No obstante, la comparación de las tasas de crecimiento procedentes de estas fuentes con las de los registros parroquiales nos hace pensar en una sobrevalo-

29 LE BRAS, H.: «Retour...», pp. 865, 873.

30 LÁZARO RUIZ, M.: La población..., pp. 30-40; y VALLEJO ZAMORA, J.: La población..., pp. 212254. 
ración de los datos correspondientes al censo de Aranda, tal y como sucedía en las comarcas riojanas estudiadas por Pedro A. Gurría y a diferencia de lo que se ha venido advirtiendo para el ámbito peninsular ${ }^{31}$.

TABLA 4: Comparación de las tasas de variación

\begin{tabular}{|c|c|c|c|c|c|}
\hline & \multicolumn{2}{|c|}{ Bautismos } & & \multicolumn{2}{|c|}{ Censos } \\
\hline & $\begin{array}{l}\text { Variación } \\
\text { porcentual }\end{array}$ & $\begin{array}{c}\text { Tasa de } \\
\text { variación }\end{array}$ & & $\begin{array}{l}\text { Variación } \\
\text { porcentual }\end{array}$ & $\begin{array}{c}\text { Tasa de } \\
\text { variación }\end{array}$ \\
\hline $1708 / 16-1748 / 56$ & $-2,46$ & $-0,07$ & $1712-1752$ & $-2,79$ & $-0,07$ \\
\hline $1748 / 56-1764 / 72$ & $-9,50$ & $-0,59$ & $1752-1768$ & $-0,64$ & $-0,04$ \\
\hline 1764/72-1783/91 & 14,68 & 0,69 & $1768-1787$ & 7,22 & 0,35 \\
\hline $1748 / 56-1783 / 91$ & 3,78 & 0,10 & $1752-1787$ & 6,53 & 0,19 \\
\hline 1708/16-1783/91 & 1,23 & 0,00 & $1712-1787$ & 3,55 & 0,05 \\
\hline
\end{tabular}

Fuente: Elaboración propia.

Independientemente de los errores que puedan observarse, es evidente que al final de la centuria su población no sólo está lejos de su máximo histórico, alcanzado en la segunda mitad del siglo XVI, sino que se sitúa por debajo del volumen de $1527-1528^{32}$. En ello se asemeja al comportamiento de los núcleos urbanos del valle del Duero y del norte de Castilla la Nueva, excepto Madrid ${ }^{33}$, aunque dentro de las ciudades de la submeseta norte haya que distinguir el moderado crecimiento de Valladolid entre 1752 y 1787 (tasa media anual del 0,42\%) del débil incremento soriano $(0,19 \%)$, que se sitúa una décima por debajo del $0,29 \%$ calculado para el conjunto de Castilla ${ }^{34}$. Con todo, el estancamiento por el que pasa esta población todavía contrasta más frente al crecimiento de las regiones vecinas de la Rioja, Navarra y Aragón, las cuales, por otra parte, están desarrollando una agricultura productiva y diversificada en este mismo tiempo ${ }^{35}$.

${ }^{31}$ GURRÍA GARCÍA, P. A.: La población..., p. 50; y MARCOS MARTíN, A.: España en los siglos XVI, XVII y XVIII. Economía y sociedad, Crítica/Caja Duero, Barcelona, 2000, p. 556.

32 Teniendo en cuenta los vecindarios del siglo XVI publicados por Enrique Díez y extrapolando la situación de 1753 como hicimos anteriormente, es probable que la población de la ciudad fuese de unos 4.450 habitantes en los años 1727-1728 y llegase a un máximo de 5.700 habitantes en 1561. DíEZ SANZ, E.: La Tierra..., p. 36.

${ }_{33}$ Sobre las diferencias observadas entre el sur de Castilla la Nueva y el resto de la región, véase MARTÍN GALÁN, M.: «La población...», p. 163.

${ }^{34}$ Este resultado ofrecido por Alberto Marcos para Valladolid parte de una corrección de las cifras originales del censo de Floridablanca basada en el conocido incremento del 5\%. MARCOS MARTíN, A.: «Evolución de la población, comportamientos demográficos y formas de la familia en el Valladolid de la Ilustración», Valladolid, historia de una ciudad, tomo II, Ayuntamiento, Valladolid, 1999, pp. 403-432.

${ }_{35}$ La Rioja Alta en su conjunto crece a un ritmo medio anual del $0,73 \%$, aunque dentro de ella la comarca de Haro lo haga a un $0,92 \%$. La Rioja Baja, soriana en el Setecientos, responde a unos valores semejantes al de la ciudad de Soria $(0,21 \%)$, aunque debe destacarse, dentro de ella, la ciudad de Calahorra con un crecimiento por encima del 0,5\%. En el reino de Aragón, Tarazona también tiene una evo- 


\section{CONCLUSIONES FINALES}

El propósito de este artículo de desvelar las peculiaridades más significativas de la evolución demográfica de la ciudad de Soria, empleando las dos fuentes utilizadas tradicionalmente por la historiografía y dentro de una perspectiva comparada, puede considerarse cumplido. En principio, alcanzar este primer nivel de investigación no exigía ninguna actualización metodológica, al tiempo que era imprescindible afrontarlo. En nuestra opinión, cualquier estudio demográfico, sociocultural o económico debe seguir tejiendo su red a partir de este punto de partida, dotado de una gran fuerza orientativa.

Por otra parte, hemos pretendido recuperar de nuestra memoria colectiva una situación, sin duda minoritaria en el siglo XVIII, pero igualmente necesitada de una reflexión historiográfica, que afectó a ciertos núcleos urbanos del interior castellano, localizados principalmente en la submeseta norte. El caso de la ciudad de Soria, con menos de 4.000 habitantes a lo largo del Setecientos, puede considerarse en cierto modo representativo de una realidad, de la que deben extraerse tres observaciones fundamentales.

En primer lugar, su dimensión poblacional, en cualquier hito cronológico del periodo estudiado aquí, continúa siendo inferior al alcanzado en el siglo XVI. En consecuencia, no estamos ante una etapa de recuperación dentro del largo plazo sino de estancamiento en unos niveles todavía inferiores a su máximo histórico del periodo moderno. En esta línea, es más que probable que, dentro del ámbito urbano castellano-leonés, sólo la ciudad de León pudiese lograr este reto, aunque tan sólo sabemos que consigue superar el nivel de 1600-1609 al comienzo del Setecientos.

En segundo lugar, hay que destacar el decrecimiento sufrido entre 1724 y 1770 aproximadamente, el cual no puede desvincularse del periodo de inestabilidad demográfica de 1706-1710, donde se vive la peor crisis de mortalidad del siglo XVIII. Las consecuencias de esta sobremortalidad, enmarcada, en cualquier caso, dentro de la Guerra de Sucesión y de un contexto económico complicado, y el posible efecto sobre la pirámide de edades son todavía hoy desconocidos. No

lución más favorable que Soria a lo largo de la centuria. Aunque entre 1709 y 1768 tan sólo incrementa su población a un ritmo medio anual del $0,27 \%$, entre los censos de Aranda y de Floridablanca su valor se eleva al $0,73 \%$. Lo mismo cabe decir de los territorios navarros más inmediatos, donde la ribera tudelana experimenta un crecimiento significativo (tasa del $0,60 \%$ en este último periodo intercensal), aunque esta cifra es superada por Pamplona, que pasa de los 11.882 a los 14.066 habitantes en este último periodo intercensal, si bien cabe añadir que en este núcleo urbano el ascenso se inicia en fechas tempranas, lo cual se traduce en un crecimiento medio acumulativo del 0,59\% entre 1727 y 1787 . GURRíA GARCÍA, P. A.: «La utilización demográfica del Catastro de Ensenada: el caso de Calahorra», Kalakorikos, 8 (2003), pp. 127-140, pp. 132-133; VALLEJO ZAMORA, J.: La población..., pp. 62-65; MIKELARENA PEÑA, F.: La evolución..., pp. 236-239; GEMBERO USTARROZ, M.: «Evolución demográfica de Pamplona entre 1553 y 1817», Príncipe de Viana, 176 (1985), pp. 745-795; FLORISTÁN IMÍZCOZ, A.: «Contrastes de crecimiento demográfico en el Valle del Ebro: la zona Media y Ribera de Navarra (siglos XVII y XVIII)», Príncipe de Viana, 190 (1990), pp. 389-404. 
obstante, la ciudad no tiene una respuesta coherente, en términos demográficos, tras la mortalidad de crisis de 1750 y decrece en una década, la de los años cincuenta, en que la mayor parte de la península está experimentando una expansión extraordinaria.

Por el contrario, y con ello llegamos al tercer elemento clave, al comienzo de los años setenta se inicia un proceso de recuperación que durará hasta el final de la centuria. Esto significa que, a diferencia de lo observado tanto en el índice regional castellano-leonés como en el del interior peninsular y Andalucía occidental, elaborados por Enrique Llopis, esta primera década deja un balance positivo en relación con la precedente en lo que a volumen de bautismos se refiere. Asimismo, debe destacarse la discreta reducción de la mortalidad adulta, que torna a ser relevante en los años ochenta, cuando las epidemias de paludismo vuelven a provocar nuevas crisis de mortalidad. Un hecho que le asemeja más a regiones del norte, como Burgos, La Rioja o Navarra, que al centro peninsular. Definitivamente, en materia de sobremortalidad, hay una clara diferencia entre la primera y la segunda mitad del siglo.

En puridad, más que cerrar el artículo con un apartado conclusivo, hemos tratado de abrir caminos de investigación o incluso de establecer balizas en un proceso de estudio destinado a comprender mejor las pequeñas comunidades urbanas del interior peninsular que, por razones complejas, se desmarcaron de la imagen típica asociada al Siglo de las Luces, pero que ocupan también una parte imprescindible de lo que José Luis Gómez Urdáñez ha denominado la España discreta. 
APÉNDICE I

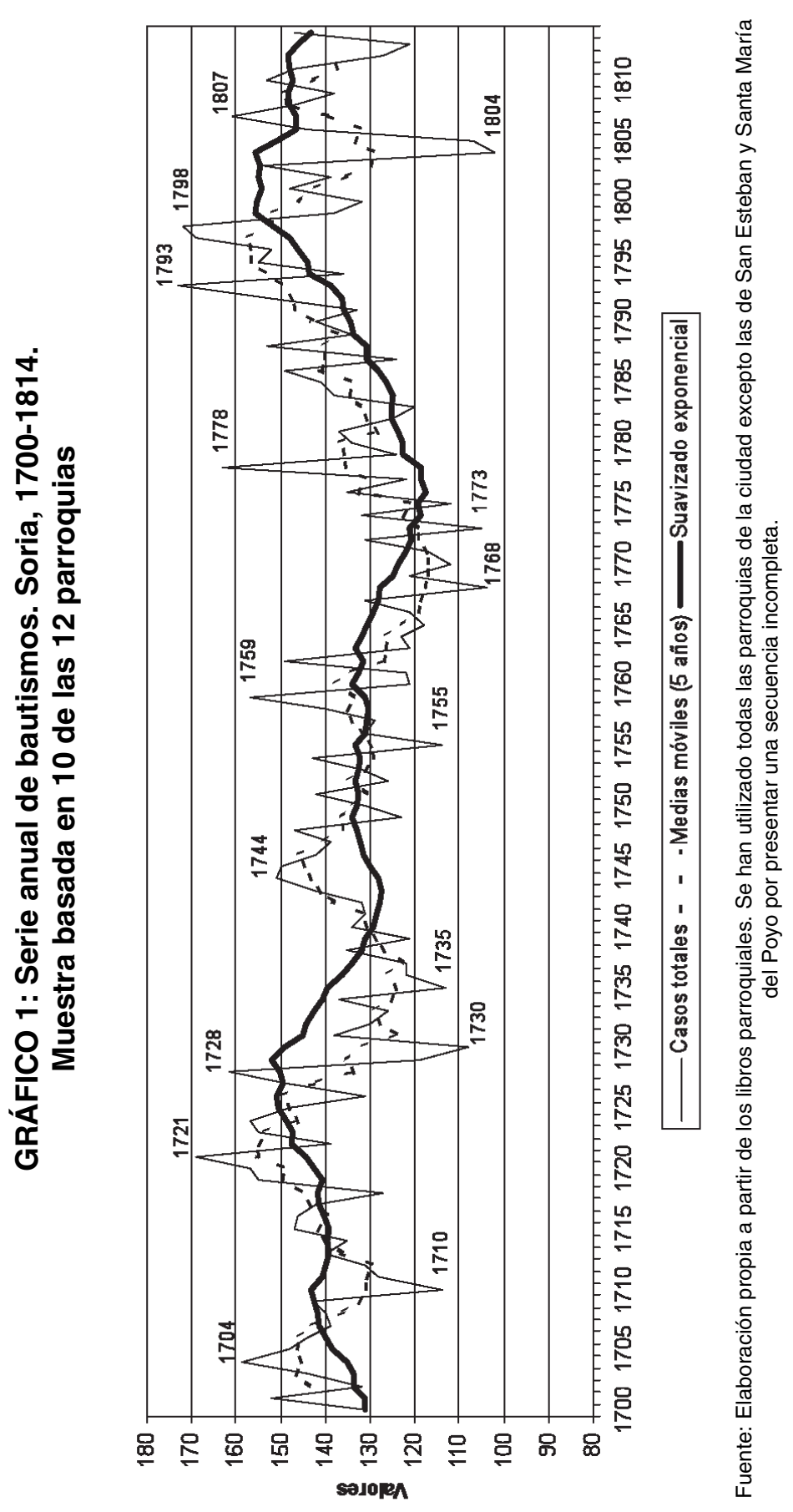




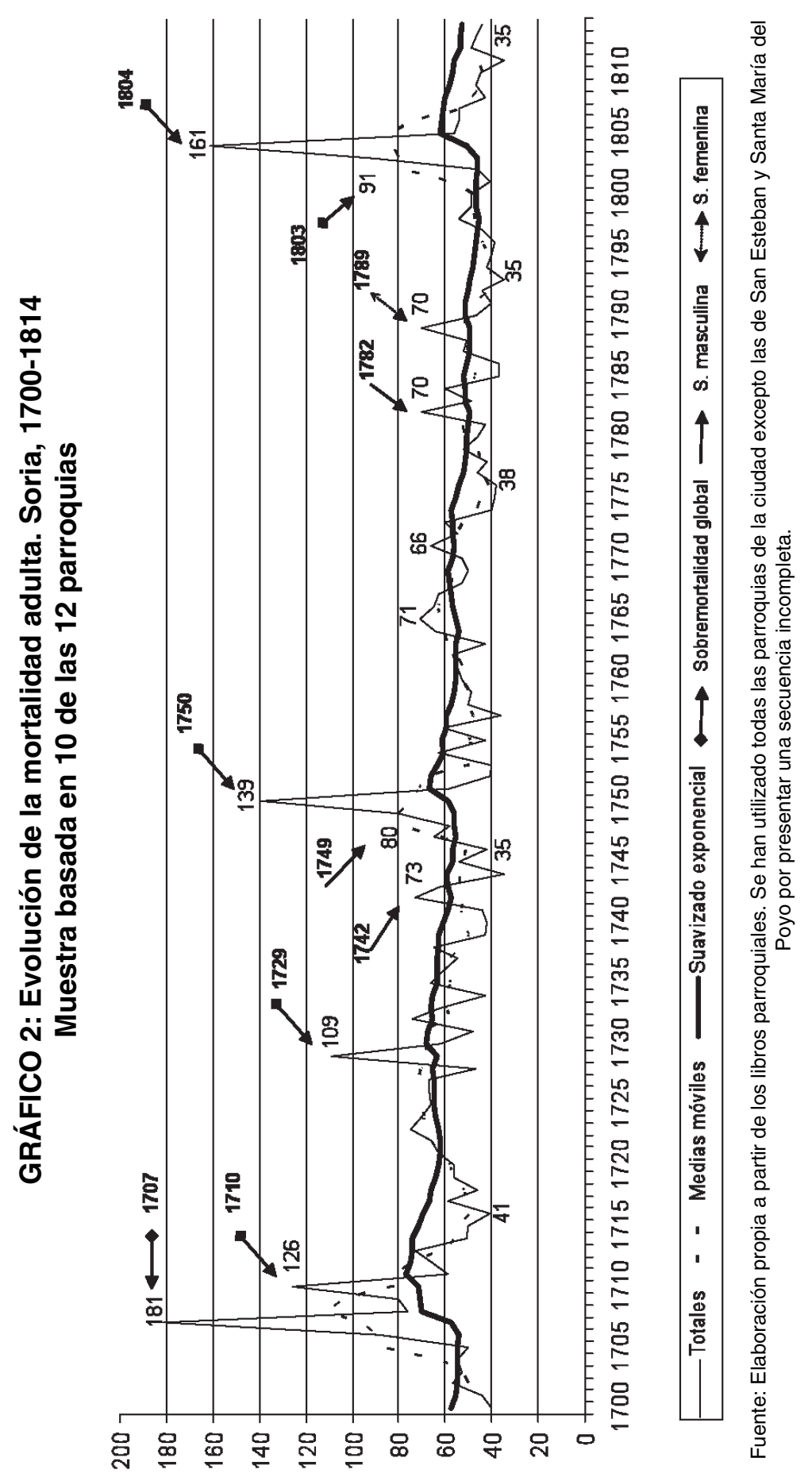




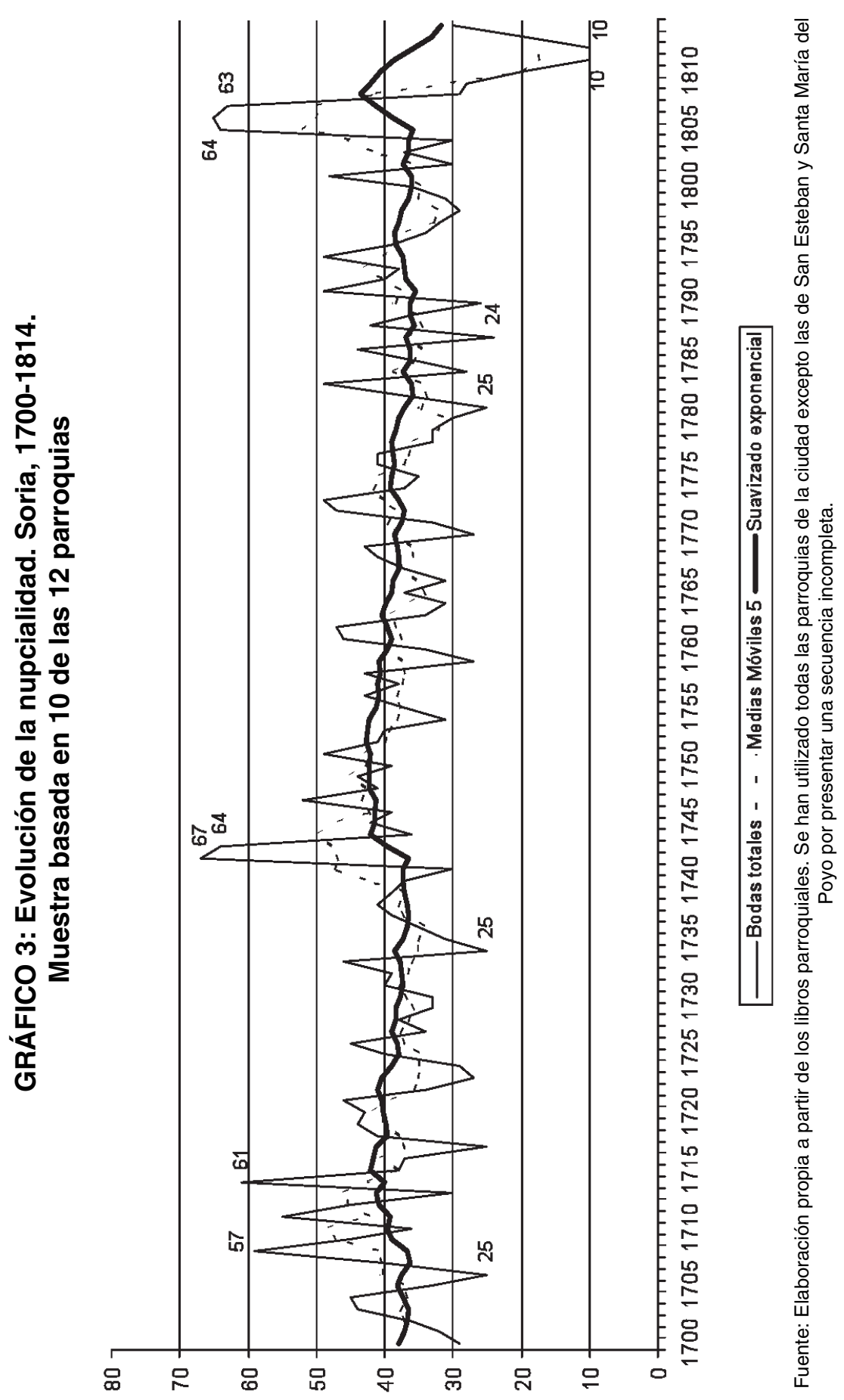




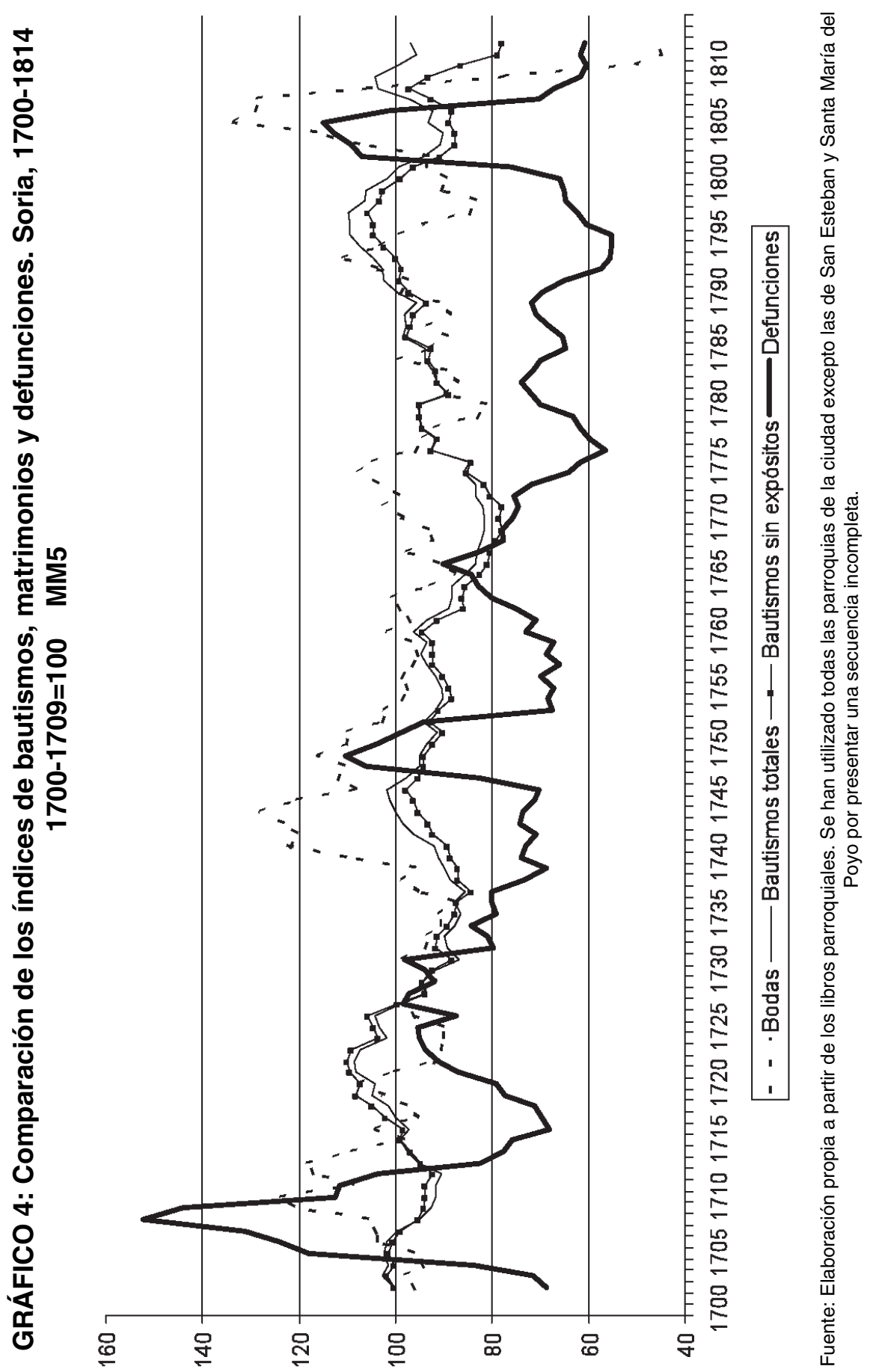




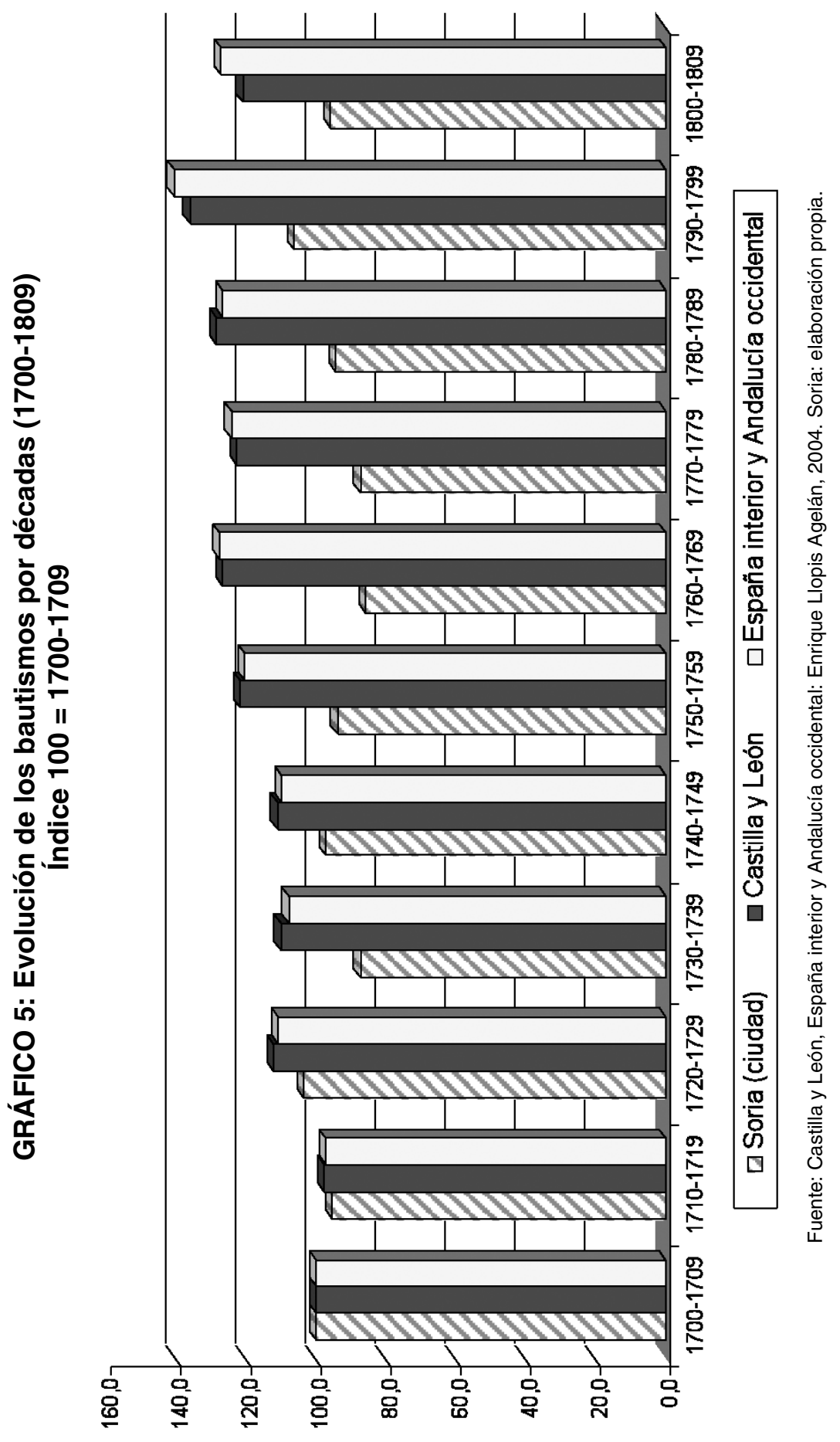




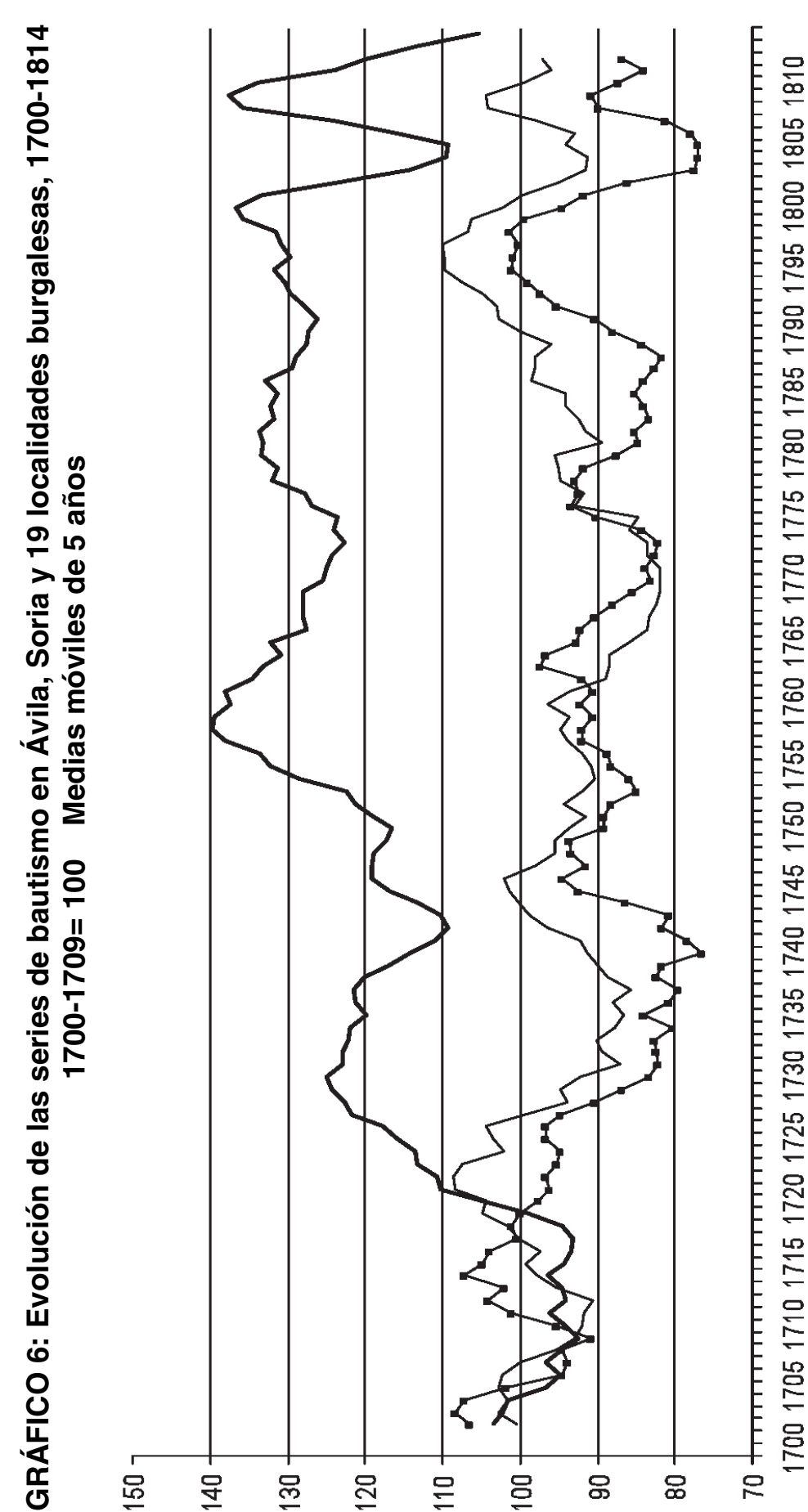

空

(8)

o 8

일

o.

중 궁

离就

음잉

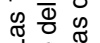

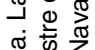

흥요

호

응 원

के

两

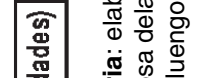

띃

क

ठ잉

๙

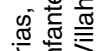

运

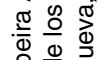

응

뜽

Ш

i⿱ 口) 을 웅

윟 잉

品

웅 흥

- $\frac{\pi}{2}$

证

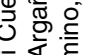

ह

$2 \pi \frac{0}{0}$

$>\mathrm{O}$

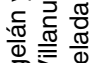

ब

응 훈?

ब

흔 $\frac{0}{0}$

พ $\frac{0}{0}$

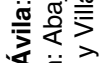

i

要

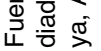




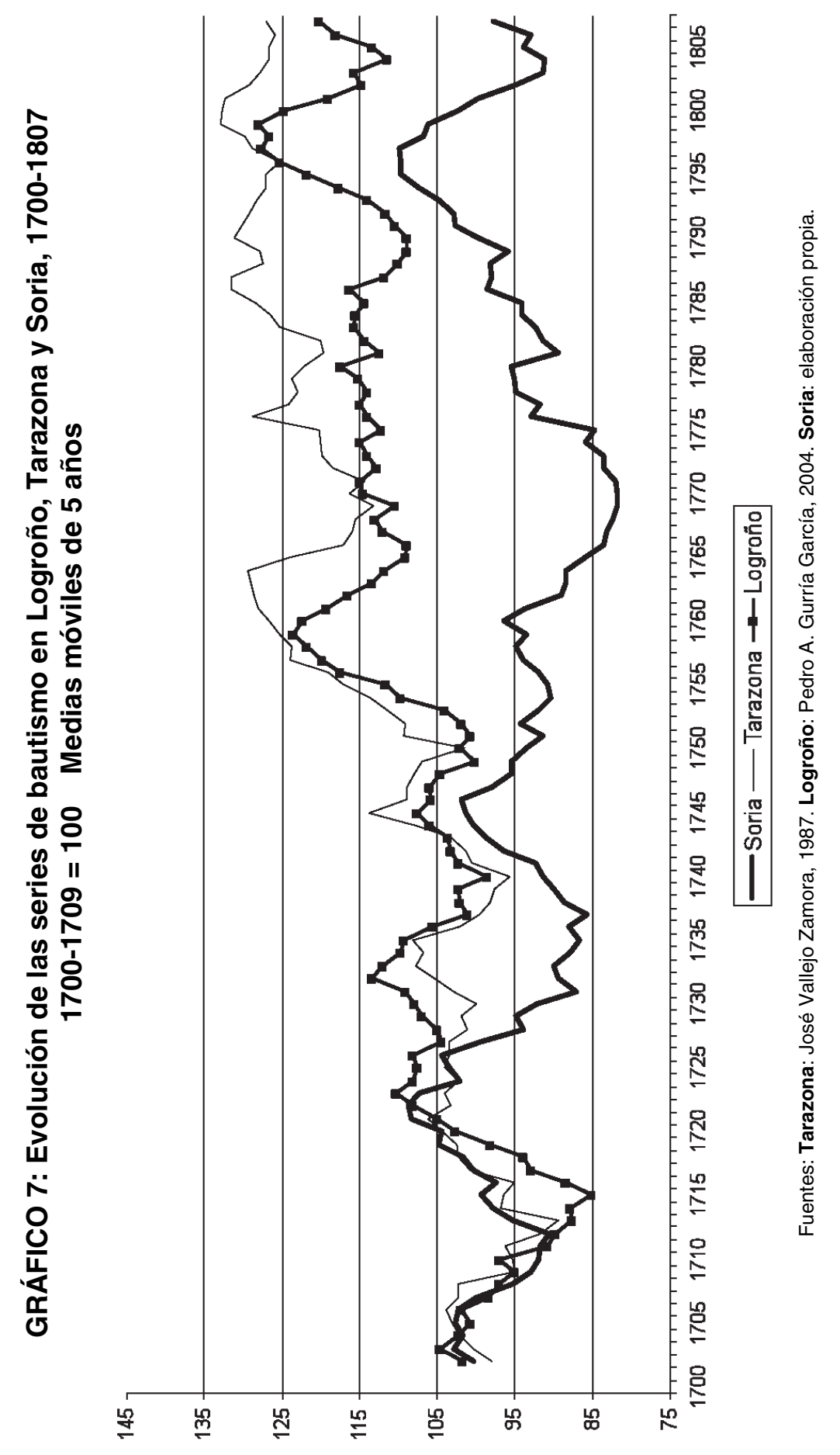




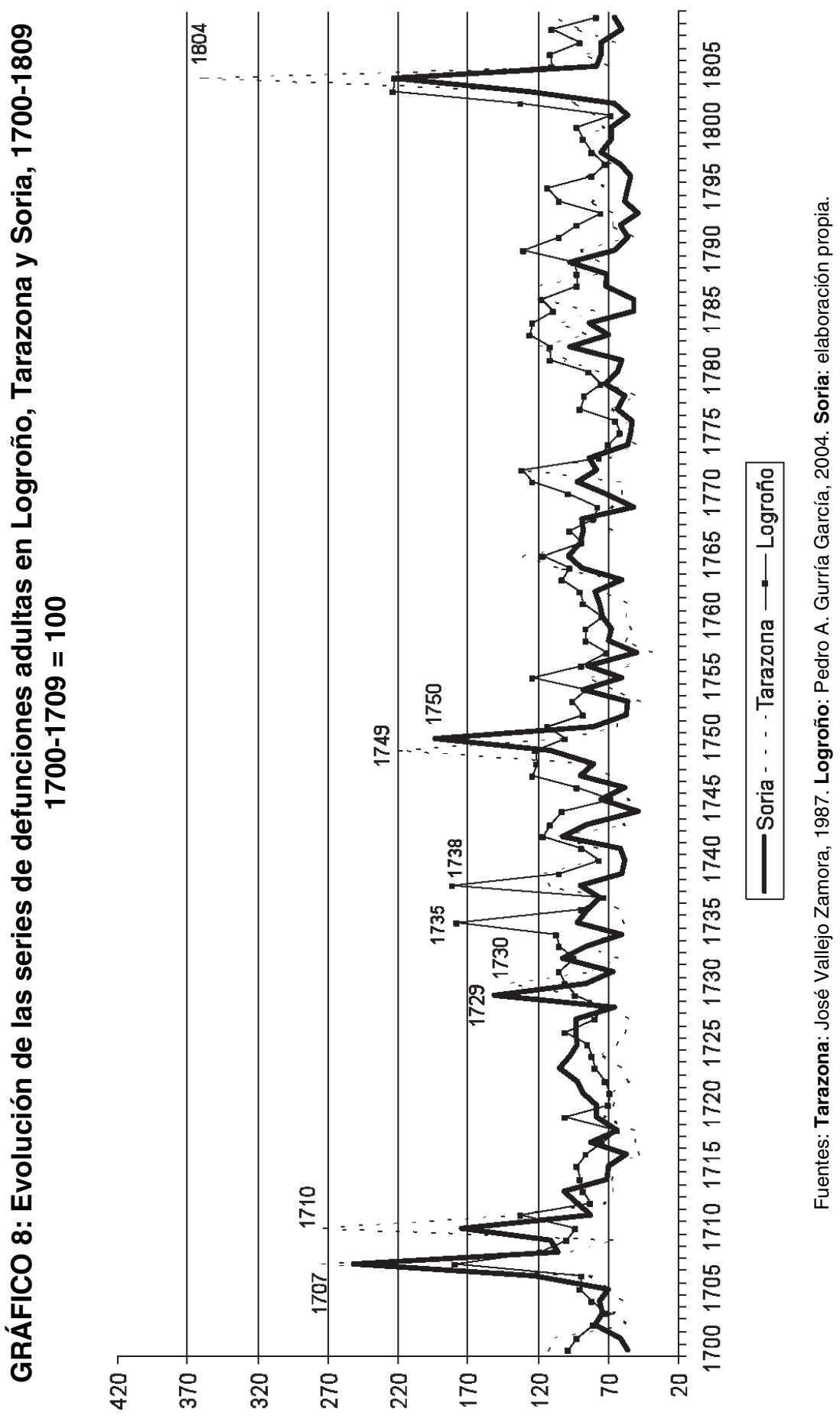




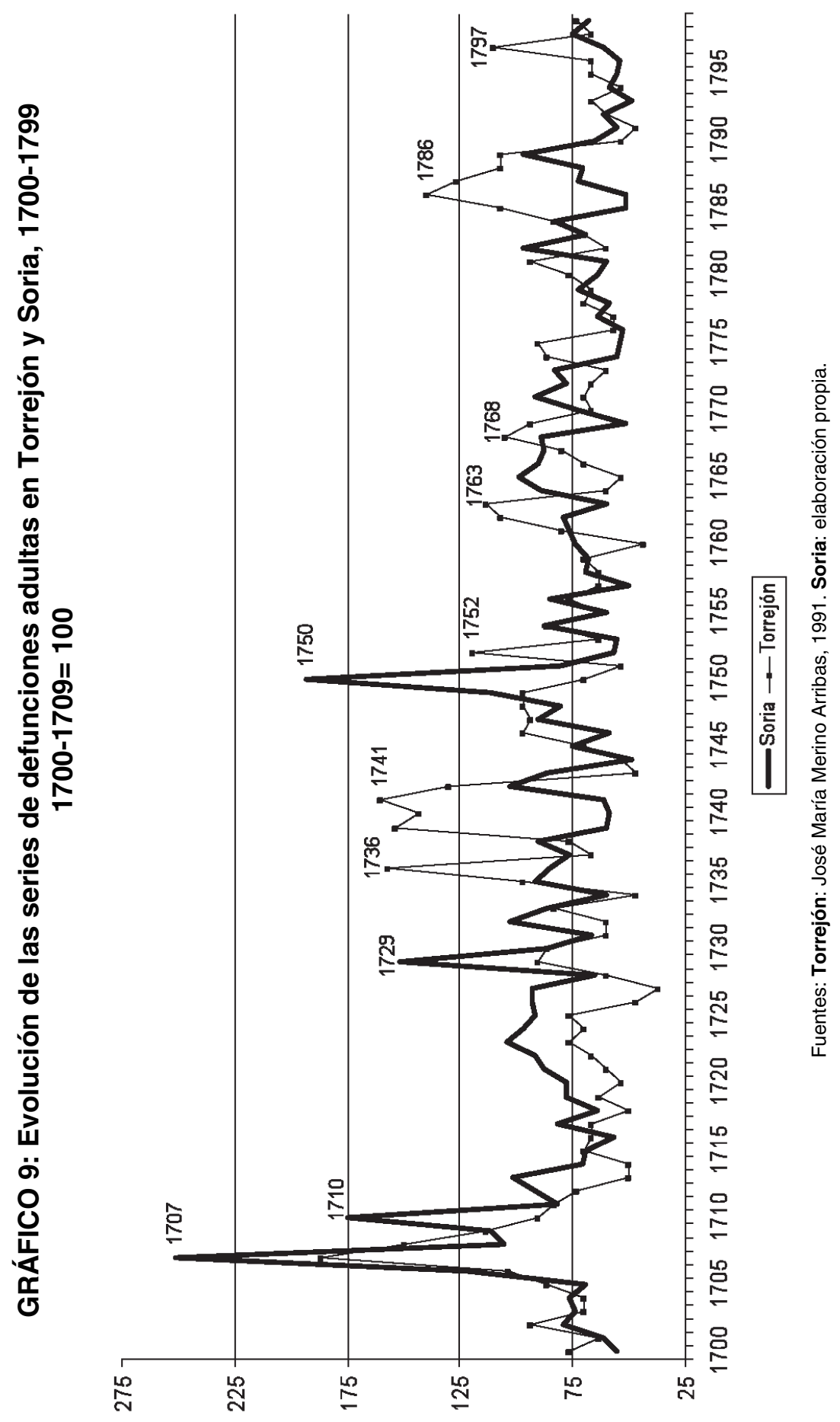




\section{APÉNDICE II}

Bautismos de la ciudad de Soria. 1700-1814 (10 parroquias)

\begin{tabular}{|c|c|c|c|c|c|c|c|}
\hline Año & Varones & Mujeres & Totales & $\begin{array}{l}\text { Varones/ } \\
\text { Mujeres }\end{array}$ & $\begin{array}{c}\text { № Índice } \\
\begin{array}{c}1700-1709 \\
=100\end{array}\end{array}$ & $\begin{array}{l}\text { Medias } \\
\text { móviles } \\
5 \text { años }\end{array}$ & $\begin{array}{c}\text { Expósitos } \\
\text { Totales } \\
(\%)\end{array}$ \\
\hline 1700 & 75 & 56 & 131 & 1,34 & 92 & & 1,53 \\
\hline 1701 & 81 & 71 & 152 & 1,14 & 106 & & 4,61 \\
\hline 1702 & 64 & 68 & 132 & 0,94 & 92 & 144 & 6,82 \\
\hline 1703 & 67 & 77 & 144 & 0,87 & 101 & 147 & 4,86 \\
\hline 1704 & 85 & 74 & 159 & 1,15 & 111 & 145 & 6,92 \\
\hline 1705 & 81 & 67 & 148 & 1,21 & 103 & 147 & 5,41 \\
\hline 1706 & 76 & 68 & 144 & 1,12 & 101 & 146 & 6,25 \\
\hline 1707 & 76 & 63 & 139 & 1,21 & 97 & 143 & 6,47 \\
\hline 1708 & 80 & 60 & 140 & 1,33 & 98 & 136 & 5,71 \\
\hline 1709 & 76 & 67 & 143 & 1,13 & 100 & 133 & 3,50 \\
\hline 1710 & 65 & 49 & 114 & 1,33 & 80 & 131 & 0,00 \\
\hline 1711 & 67 & 62 & 128 & 1,08 & 90 & 131 & 0,78 \\
\hline 1712 & 62 & 68 & 131 & 0,91 & 92 & 130 & 2,29 \\
\hline 1713 & 73 & 67 & 140 & 1,09 & 98 & 136 & 5,71 \\
\hline 1714 & 75 & 60 & 135 & 1,25 & 94 & 140 & 7,41 \\
\hline 1715 & 87 & 60 & 147 & 1,45 & 103 & 142 & 10,88 \\
\hline 1716 & 71 & 75 & 146 & 0,95 & 102 & 139 & 4,11 \\
\hline 1717 & 65 & 77 & 142 & 0,84 & 99 & 143 & 4,23 \\
\hline 1718 & 58 & 69 & 127 & 0,84 & 89 & 145 & 3,15 \\
\hline 1719 & 76 & 79 & 155 & 0,96 & 108 & 150 & 2,58 \\
\hline 1720 & 83 & 74 & 157 & 1,12 & 110 & 149 & 3,82 \\
\hline 1721 & 94 & 75 & 169 & 1,25 & 118 & 155 & 3,55 \\
\hline 1722 & 72 & 67 & 139 & 1,07 & 97 & 155 & 3,60 \\
\hline 1723 & 79 & 76 & 155 & 1,04 & 108 & 154 & 7,74 \\
\hline 1724 & 75 & 82 & 157 & 0,91 & 110 & 146 & 5,10 \\
\hline 1725 & 70 & 78 & 148 & 0,90 & 103 & 148 & 6,08 \\
\hline 1726 & 73 & 58 & 131 & 1,26 & 92 & 149 & 3,82 \\
\hline 1727 & 74 & 75 & 149 & 0,99 & 104 & 142 & 5,37 \\
\hline 1728 & 85 & 77 & 162 & 1,10 & 113 & 134 & 6,79 \\
\hline 1729 & 65 & 54 & 119 & 1,20 & 83 & 135 & 6,72 \\
\hline 1730 & 59 & 49 & 108 & 1,20 & 76 & 131 & 8,33 \\
\hline 1731 & 68 & 70 & 138 & 0,97 & 97 & 124 & 8,70 \\
\hline 1732 & 61 & 69 & 130 & 0,88 & 91 & 128 & 6,15 \\
\hline 1733 & 57 & 69 & 126 & 0,83 & 88 & 129 & 2,38 \\
\hline 1734 & 73 & 64 & 137 & 1,14 & 96 & 126 & 5,84 \\
\hline
\end{tabular}


(Continuación)

\begin{tabular}{|c|c|c|c|c|c|c|c|}
\hline Año & Varones & Mujeres & Totales & $\begin{array}{l}\text { Varones/ } \\
\text { Mujeres }\end{array}$ & $\begin{array}{c}\text { No Índice } \\
\begin{array}{c}1700-1709 \\
=100\end{array}\end{array}$ & $\begin{array}{l}\text { Medias } \\
\text { móviles } \\
5 \text { años }\end{array}$ & $\begin{array}{c}\text { Expósitos/ } \\
\text { Totales } \\
(\%)\end{array}$ \\
\hline 1735 & 62 & 51 & 113 & 1,22 & 79 & 124 & 13,27 \\
\hline 1736 & 62 & 60 & 122 & 1,03 & 85 & 126 & 4,92 \\
\hline 1737 & 69 & 53 & 122 & 1,30 & 85 & 123 & 7,38 \\
\hline 1738 & 71 & 64 & 135 & 1,11 & 94 & 127 & 8,15 \\
\hline 1739 & 68 & 53 & 121 & 1,28 & 85 & 129 & 8,26 \\
\hline 1740 & 70 & 64 & 134 & 1,09 & 94 & 131 & 7,46 \\
\hline 1741 & 62 & 69 & 131 & 0,90 & 92 & 132 & 9,92 \\
\hline 1742 & 56 & 76 & 132 & 0,74 & 92 & 138 & 5,30 \\
\hline 1743 & 79 & 63 & 142 & 1,25 & 99 & 141 & 9,86 \\
\hline 1744 & 77 & 74 & 151 & 1,04 & 106 & 143 & 11,92 \\
\hline 1745 & 83 & 67 & 150 & 1,24 & 105 & 145 & 14,00 \\
\hline 1746 & 77 & 65 & 142 & 1,18 & 99 & 146 & 6,34 \\
\hline 1747 & 72 & 67 & 139 & 1,07 & 97 & 140 & 5,76 \\
\hline 1748 & 79 & 68 & 147 & 1,16 & 103 & 136 & 6,12 \\
\hline 1749 & 57 & 66 & 123 & 0,86 & 86 & 136 & 5,69 \\
\hline 1750 & 67 & 64 & 131 & 1,05 & 92 & 134 & 7,63 \\
\hline 1751 & 85 & 57 & 142 & 1,49 & 99 & 131 & 5,63 \\
\hline 1752 & 68 & 58 & 126 & 1,17 & 88 & 135 & 5,56 \\
\hline 1753 & 66 & 66 & 132 & 1,00 & 92 & 131 & 6,82 \\
\hline 1754 & 70 & 73 & 143 & 0,96 & 100 & 129 & 5,59 \\
\hline 1755 & 60 & 54 & 114 & 1,11 & 80 & 130 & 5,26 \\
\hline 1756 & 72 & 59 & 131 & 1,22 & 92 & 131 & 12,98 \\
\hline 1757 & 67 & 62 & 129 & 1,08 & 90 & 134 & 3,10 \\
\hline 1758 & 63 & 77 & 140 & 0,82 & 98 & 136 & 6,43 \\
\hline 1759 & 80 & 77 & 157 & 1,04 & 110 & 134 & 5,10 \\
\hline 1760 & 63 & 58 & 121 & 1,09 & 85 & 138 & 9,92 \\
\hline 1761 & 57 & 65 & 122 & 0,88 & 85 & 134 & 6,56 \\
\hline 1762 & 80 & 69 & 149 & 1,16 & 104 & 127 & 7,38 \\
\hline 1763 & 57 & 64 & 121 & 0,89 & 85 & 127 & 8,26 \\
\hline 1764 & 59 & 64 & 123 & 0,92 & 86 & 126 & 8,94 \\
\hline 1765 & 59 & 59 & 118 & 1,00 & 83 & 123 & 6,78 \\
\hline 1766 & 62 & 59 & 121 & 1,05 & 85 & 119 & 9,09 \\
\hline 1767 & 68 & 63 & 131 & 1,08 & 92 & 119 & 12,21 \\
\hline 1768 & 53 & 51 & 104 & 1,04 & 73 & 118 & 2,88 \\
\hline 1769 & 67 & 54 & 121 & 1,24 & 85 & 117 & 9,92 \\
\hline 1770 & 62 & 50 & 112 & 1,24 & 78 & 117 & 9,82 \\
\hline 1771 & 64 & 53 & 117 & 1,21 & 82 & 117 & 13,68 \\
\hline
\end{tabular}


(Continuación)

\begin{tabular}{|c|c|c|c|c|c|c|c|}
\hline Año & Varones & Mujeres & Totales & $\begin{array}{l}\text { Varones/ } \\
\text { Mujeres }\end{array}$ & $\begin{array}{c}N^{\circ} \text { Índice } \\
1700-1709 \\
=100\end{array}$ & $\begin{array}{l}\text { Medias } \\
\text { móviles } \\
5 \text { años }\end{array}$ & $\begin{array}{c}\text { Expósitos/ } \\
\text { Totales } \\
(\%)\end{array}$ \\
\hline 1772 & 66 & 65 & 131 & 1,02 & 92 & 119 & 6,87 \\
\hline 1773 & 57 & 48 & 105 & 1,19 & 73 & 119 & 7,62 \\
\hline 1774 & 67 & 65 & 132 & 1,03 & 92 & 123 & 5,30 \\
\hline 1775 & 56 & 56 & 112 & 1,00 & 78 & 121 & 2,68 \\
\hline 1776 & 60 & 75 & 135 & 0,80 & 94 & 133 & 6,67 \\
\hline 1777 & 60 & 62 & 122 & 0,97 & 85 & 131 & 4,10 \\
\hline 1778 & 77 & 86 & 163 & 0,90 & 114 & 136 & 6,75 \\
\hline 1779 & 49 & 75 & 124 & 0,65 & 87 & 136 & 6,45 \\
\hline 1780 & 68 & 66 & 134 & 1,03 & 94 & 137 & 2,99 \\
\hline 1781 & 74 & 63 & 137 & 1,17 & 96 & 128 & 5,11 \\
\hline 1782 & 64 & 61 & 125 & 1,05 & 87 & 131 & 6,40 \\
\hline 1783 & 55 & 65 & 120 & 0,85 & 84 & 132 & 5,83 \\
\hline 1784 & 75 & 63 & 138 & 1,19 & 97 & 135 & 5,07 \\
\hline 1785 & 63 & 78 & 141 & 0,81 & 99 & 134 & 6,38 \\
\hline 1786 & 84 & 65 & 149 & 1,29 & 104 & 141 & 5,37 \\
\hline 1787 & 68 & 56 & 124 & 1,21 & 87 & 140 & 8,06 \\
\hline 1788 & 82 & 71 & 153 & 1,15 & 107 & 140 & 4,58 \\
\hline 1789 & 67 & 67 & 134 & 1,00 & 94 & 137 & 6,72 \\
\hline 1790 & 61 & 81 & 142 & 0,75 & 99 & 143 & 8,45 \\
\hline 1791 & 74 & 59 & 133 & 1,25 & 93 & 147 & 9,02 \\
\hline 1792 & 73 & 79 & 152 & 0,92 & 106 & 147 & 7,89 \\
\hline 1793 & 92 & 81 & 173 & 1,14 & 121 & 150 & 8,09 \\
\hline 1794 & 64 & 72 & 136 & 0,89 & 95 & 154 & 10,29 \\
\hline 1795 & 74 & 81 & 155 & 0,91 & 108 & 157 & 10,97 \\
\hline 1796 & 77 & 75 & 152 & 1,03 & 106 & 157 & 9,87 \\
\hline 1797 & 80 & 89 & 169 & 0,90 & 118 & 157 & 8,28 \\
\hline 1798 & 85 & 87 & 172 & 0,98 & 120 & 153 & 8,14 \\
\hline 1799 & 83 & 55 & 138 & 1,51 & 97 & 152 & 5,80 \\
\hline 1800 & 69 & 63 & 132 & 1,10 & 92 & 146 & 7,58 \\
\hline 1801 & 77 & 71 & 148 & 1,08 & 103 & 142 & 10,14 \\
\hline 1802 & 70 & 69 & 139 & 1,01 & 97 & 135 & 6,47 \\
\hline 1803 & 69 & 85 & 154 & 0,81 & 108 & 130 & 10,39 \\
\hline 1804 & 50 & 52 & 102 & 0,96 & 71 & 129 & 9,80 \\
\hline 1805 & 47 & 60 & 107 & 0,78 & 75 & 134 & 7,48 \\
\hline 1806 & 61 & 83 & 144 & 0,73 & 101 & 132 & 8,33 \\
\hline 1807 & 78 & 83 & 161 & 0,94 & 113 & 139 & 13,04 \\
\hline 1808 & 82 & 65 & 147 & 1,26 & 103 & 149 & 8,16 \\
\hline
\end{tabular}


(Continuación)

\begin{tabular}{cccccccc}
\hline Año & Varones & Mujeres & Totales & $\begin{array}{c}\text { Varones/ } \\
\text { Mujeres }\end{array}$ & $\begin{array}{c}\text { No Índice } \\
\mathbf{1 7 0 0 - 1 7 0 9} \\
\mathbf{= 1 0 0}\end{array}$ & $\begin{array}{c}\text { Medias } \\
\text { móviles } \\
\mathbf{5} \text { años }\end{array}$ & $\begin{array}{c}\text { Expósitos/ } \\
\text { Totales } \\
(\%)\end{array}$ \\
\hline 1809 & 63 & 75 & 138 & 0,84 & 97 & 149 & 12,32 \\
1810 & 79 & 74 & 153 & 1,07 & 107 & 142 & 13,73 \\
1811 & 95 & 52 & 147 & 1,83 & 103 & 137 & 21,09 \\
1812 & 61 & 66 & 127 & 0,92 & 89 & 139 & 22,83 \\
1813 & 66 & 55 & 121 & 1,20 & 85 & & 31,40 \\
1814 & 86 & 61 & 147 & 1,41 & 103 & & 23,81 \\
\hline
\end{tabular}

Fuente: Elaboración propia a partir de los libros parroquiales. Se han utilizado todas las parroquias de la ciudad excepto las de San Esteban y Santa María del Poyo por presentar una secuencia incompleta.

Bautismos de expósitos en la ciudad de Soria. 1700-1814

\begin{tabular}{ccccccc}
\hline Año & Varones & Mujeres & Totales & $\begin{array}{c}\text { Varones/ } \\
\text { Mujeres }\end{array}$ & $\begin{array}{c}\text { No Índice } \\
\mathbf{1 7 0 0 - 1 7 0 9} \\
\mathbf{= 1 0 0}\end{array}$ & $\begin{array}{c}\text { Medias } \\
\text { móviles } \\
\mathbf{5} \text { años }\end{array}$ \\
\hline 1700 & 0 & 2 & 2 & 0,00 & 27 & \\
1701 & 5 & 2 & 7 & 2,50 & 93 & \\
1702 & 5 & 4 & 9 & 1,25 & 120 & 7 \\
1703 & 5 & 2 & 7 & 2,50 & 93 & 8 \\
1704 & 5 & 6 & 11 & 0,83 & 147 & 9 \\
1705 & 4 & 4 & 8 & 1,00 & 107 & 9 \\
1706 & 2 & 7 & 9 & 0,29 & 120 & 9 \\
1707 & 6 & 3 & 9 & 2,00 & 120 & 8 \\
1708 & 5 & 3 & 8 & 1,67 & 107 & 6 \\
1709 & 4 & 1 & 5 & 4,00 & 67 & 5 \\
1710 & 0 & 0 & 0 & - & 0 & 3 \\
1711 & 1 & 0 & 1 & - & 13 & 3 \\
1712 & 2 & 1 & 3 & - & 40 & 4 \\
1713 & 3 & 5 & 8 & 0,60 & 107 & 8 \\
1714 & 3 & 7 & 10 & 0,43 & 133 & 9 \\
1715 & 10 & 6 & 16 & 1,67 & 213 & 9 \\
1716 & 2 & 4 & 6 & 0,50 & 80 & 8 \\
1717 & 5 & 1 & 6 & - & 80 & 7 \\
1718 & 2 & 2 & 4 & - & 53 & 5 \\
1719 & 3 & 1 & 4 & 3,00 & 53 & 5 \\
1720 & 4 & 2 & 6 & 2,00 & 80 & 5 \\
1721 & 5 & 1 & 6 & - & 80 & 7 \\
1722 & 3 & 2 & 5 & 1,50 & 67 & 7 \\
\hline & & & & & & \\
\hline
\end{tabular}

(Continúa) 
(Continuación)

\begin{tabular}{|c|c|c|c|c|c|c|}
\hline Año & Varones & Mujeres & Totales & $\begin{array}{l}\text { Varones/ } \\
\text { Mujeres }\end{array}$ & $\begin{array}{c}N^{\circ} \text { Índice } \\
1700-1709 \\
=100\end{array}$ & $\begin{array}{c}\text { Medias } \\
\text { móviles } \\
5 \text { años }\end{array}$ \\
\hline 1723 & 9 & 3 & 12 & 3,00 & 160 & 8 \\
\hline 1724 & 5 & 3 & 8 & 1,67 & 107 & 8 \\
\hline 1725 & 4 & 5 & 9 & 0,80 & 120 & 8 \\
\hline 1726 & 2 & 3 & 5 & 0,67 & 67 & 8 \\
\hline 1727 & 4 & 4 & 8 & 1,00 & 107 & 8 \\
\hline 1728 & 8 & 3 & 11 & 2,67 & 147 & 8 \\
\hline 1729 & 7 & 1 & 8 & - & 107 & 10 \\
\hline 1730 & 4 & 5 & 9 & 0,80 & 120 & 10 \\
\hline 1731 & 5 & 7 & 12 & 0,71 & 160 & 8 \\
\hline 1732 & 3 & 5 & 8 & 0,60 & 107 & 8 \\
\hline 1733 & 1 & 2 & 3 & 0,50 & 40 & 9 \\
\hline 1734 & 4 & 4 & 8 & 1,00 & 107 & 8 \\
\hline 1735 & 10 & 5 & 15 & 2,00 & 200 & 8 \\
\hline 1736 & 4 & 2 & 6 & 2,00 & 80 & 10 \\
\hline 1737 & 4 & 5 & 9 & 0,80 & 120 & 10 \\
\hline 1738 & 5 & 6 & 11 & 0,83 & 147 & 9 \\
\hline 1739 & 6 & 4 & 10 & 1,50 & 133 & 11 \\
\hline 1740 & 5 & 5 & 10 & 1,00 & 133 & 10 \\
\hline 1741 & 6 & 7 & 13 & 0,86 & 173 & 11 \\
\hline 1742 & 3 & 4 & 7 & - & 93 & 12 \\
\hline 1743 & 7 & 7 & 14 & 1,00 & 187 & 15 \\
\hline 1744 & 9 & 9 & 18 & 1,00 & 240 & 14 \\
\hline 1745 & 11 & 10 & 21 & 1,10 & 280 & 14 \\
\hline 1746 & 2 & 7 & 9 & 0,29 & 120 & 13 \\
\hline 1747 & 7 & 1 & 8 & 7,00 & 107 & 11 \\
\hline 1748 & 5 & 4 & 9 & 1,25 & 120 & 9 \\
\hline 1749 & 2 & 5 & 7 & 0,40 & 93 & 8 \\
\hline 1750 & 2 & 8 & 10 & 0,25 & 133 & 8 \\
\hline 1751 & 4 & 4 & 8 & 1,00 & 107 & 8 \\
\hline 1752 & 2 & 5 & 7 & 0,40 & 93 & 8 \\
\hline 1753 & 3 & 6 & 9 & 0,50 & 120 & 8 \\
\hline 1754 & 5 & 3 & 8 & 1,67 & 107 & 9 \\
\hline 1755 & 3 & 3 & 6 & 1,00 & 80 & 9 \\
\hline 1756 & 9 & 8 & 17 & 1,13 & 227 & 9 \\
\hline 1757 & 3 & 1 & 4 & 3,00 & 53 & 9 \\
\hline 1758 & 4 & 5 & 9 & 0,80 & 120 & 10 \\
\hline 1759 & 6 & 2 & 8 & 3,00 & 107 & 8 \\
\hline
\end{tabular}


(Continuación)

\begin{tabular}{|c|c|c|c|c|c|c|}
\hline Año & Varones & Mujeres & Totales & $\begin{array}{l}\text { Varones/ } \\
\text { Mujeres }\end{array}$ & $\begin{array}{c}N^{\circ} \text { Índice } \\
1700-1709 \\
=100\end{array}$ & $\begin{array}{c}\text { Medias } \\
\text { móviles } \\
5 \text { años }\end{array}$ \\
\hline 1760 & 7 & 5 & 12 & 1,40 & 160 & 10 \\
\hline 1761 & 4 & 4 & 8 & 1,00 & 107 & 10 \\
\hline 1762 & 4 & 7 & 11 & 0,57 & 147 & 10 \\
\hline 1763 & 4 & 6 & 10 & 0,67 & 133 & 10 \\
\hline 1764 & 7 & 4 & 11 & 1,75 & 147 & 10 \\
\hline 1765 & 4 & 4 & 8 & 1,00 & 107 & 11 \\
\hline 1766 & 3 & 8 & 11 & 0,38 & 147 & 10 \\
\hline 1767 & 7 & 9 & 16 & 0,78 & 213 & 10 \\
\hline 1768 & 1 & 2 & 3 & 0,50 & 40 & 11 \\
\hline 1769 & 8 & 4 & 12 & 2,00 & 160 & 12 \\
\hline 1770 & 4 & 7 & 11 & 0,57 & 147 & 10 \\
\hline 1771 & 7 & 9 & 16 & 0,78 & 213 & 11 \\
\hline 1772 & 5 & 4 & 9 & 1,25 & 120 & 10 \\
\hline 1773 & 4 & 4 & 8 & 1,00 & 107 & 9 \\
\hline 1774 & 4 & 3 & 7 & 1,33 & 93 & 7 \\
\hline 1775 & 2 & 1 & 3 & 2,00 & 40 & 6 \\
\hline 1776 & 3 & 6 & 9 & 0,50 & 120 & 7 \\
\hline 1777 & 2 & 3 & 5 & 0,67 & 67 & 7 \\
\hline 1778 & 8 & 3 & 11 & 2,67 & 147 & 7 \\
\hline 1779 & 4 & 4 & 8 & 1,00 & 107 & 7 \\
\hline 1780 & 1 & 3 & 4 & 0,33 & 53 & 8 \\
\hline 1781 & 5 & 2 & 7 & 2,50 & 93 & 7 \\
\hline 1782 & 2 & 6 & 8 & 0,33 & 107 & 7 \\
\hline 1783 & 2 & 5 & 7 & 0,40 & 93 & 8 \\
\hline 1784 & 5 & 2 & 7 & 2,50 & 93 & 8 \\
\hline 1785 & 5 & 4 & 9 & 1,25 & 120 & 8 \\
\hline 1786 & 4 & 4 & 8 & 1,00 & 107 & 8 \\
\hline 1787 & 5 & 5 & 10 & - & 133 & 9 \\
\hline 1788 & 3 & 4 & 7 & 0,75 & 93 & 9 \\
\hline 1789 & 3 & 6 & 9 & 0,50 & 120 & 10 \\
\hline 1790 & 6 & 6 & 12 & 1,00 & 160 & 10 \\
\hline 1791 & 6 & 6 & 12 & 1,00 & 160 & 12 \\
\hline 1792 & 4 & 8 & 12 & 0,50 & 160 & 13 \\
\hline 1793 & 7 & 7 & 14 & 1,00 & 187 & 14 \\
\hline 1794 & 6 & 8 & 14 & 0,75 & 187 & 14 \\
\hline 1795 & 5 & 12 & 17 & 0,42 & 227 & 15 \\
\hline 1796 & 8 & 7 & 15 & 1,14 & 200 & 15 \\
\hline
\end{tabular}


(Continuación)

\begin{tabular}{ccccccc}
\hline Año & Varones & Mujeres & Totales & $\begin{array}{c}\text { Varones/ } \\
\text { Mujeres }\end{array}$ & $\begin{array}{c}\text { No Índice } \\
\mathbf{1 7 0 0 - 1 7 0 9} \\
\mathbf{= 1 0 0}\end{array}$ & $\begin{array}{c}\text { Medias } \\
\text { móviles } \\
\mathbf{5} \text { años }\end{array}$ \\
\hline 1797 & 6 & 8 & 14 & 0,75 & 187 & 14 \\
1798 & 8 & 6 & 14 & 1,33 & 187 & 12 \\
1799 & 6 & 2 & 8 & 3,00 & 107 & 12 \\
1800 & 5 & 5 & 10 & 1,00 & 133 & 11 \\
1801 & 7 & 8 & 15 & 0,88 & 200 & 12 \\
1802 & 4 & 5 & 9 & 0,80 & 120 & 12 \\
1803 & 8 & 8 & 16 & 1,00 & 213 & 12 \\
1804 & 6 & 4 & 10 & 1,50 & 133 & 11 \\
1805 & 4 & 4 & 8 & 1,00 & 107 & 13 \\
1806 & 5 & 7 & 12 & 0,71 & 160 & 13 \\
1807 & 8 & 13 & 21 & 0,62 & 280 & 14 \\
1808 & 6 & 6 & 12 & 1,00 & 160 & 17 \\
1809 & 9 & 8 & 17 & 1,13 & 227 & 20 \\
1810 & 12 & 9 & 21 & 1,33 & 280 & 22 \\
1811 & 16 & 15 & 31 & 1,07 & 413 & 27 \\
1812 & 15 & 14 & 29 & 1,07 & 387 & 31 \\
1813 & 20 & 18 & 38 & 1,11 & 507 & \\
1814 & 22 & 13 & 35 & 1,69 & 467 &
\end{tabular}

Fuente: Elaboración propia a partir de los libros parroquiales. Los bautismos de expósitos están centralizados básicamente en la colegiata de San Pedro. Hay también casos en las parroquias de Santo Tomé, San Nicolás y Santa María la Mayor.

Bodas en la ciudad de Soria. 1700-1814 (10 parroquias)

\begin{tabular}{cccccccc}
\hline Año & $\begin{array}{c}\text { Bodas } \\
\text { Totales }\end{array}$ & $\begin{array}{c}\text { Nos Índices } \\
\mathbf{1 7 0 0 - 1 7 0 9} \\
\mathbf{= 1 0 0}\end{array}$ & $\begin{array}{c}\text { Medias } \\
\text { móviles } \\
\mathbf{5} \text { años }\end{array}$ & $\begin{array}{c}\text { Año } \\
\text { Bodas } \\
\text { Totales }\end{array}$ & $\begin{array}{c}\text { Nos Índices } \\
\mathbf{1 7 0 0 - 1 7 0 9} \\
\mathbf{= 1 0 0}\end{array}$ & $\begin{array}{c}\text { Medias } \\
\text { móviles } \\
\mathbf{5} \text { años }\end{array}$ \\
\hline 1700 & 29 & 75 & & 1711 & 55 & 142 & 42 \\
1701 & 32 & 82 & & 1712 & 45 & 116 & 45 \\
1702 & 36 & 93 & 37 & 1713 & 30 & 77 & 46 \\
1703 & 44 & 113 & 38 & 1714 & 61 & 157 & 42 \\
1704 & 45 & 116 & 37 & 1715 & 38 & 98 & 38 \\
1705 & 33 & 85 & 37 & 1716 & 37 & 95 & 40 \\
1706 & 25 & 64 & 40 & 1717 & 25 & 64 & 37 \\
1707 & 40 & 103 & 40 & 1718 & 41 & 106 & 38 \\
1708 & 59 & 152 & 41 & 1719 & 44 & 113 & 40 \\
1709 & 45 & 116 & 47 & 1720 & 43 & 111 & 42 \\
1710 & 36 & 93 & 48 & 1721 & 46 & 119 & 39 \\
\hline
\end{tabular}

(Continúa) 
(Continuación)

\begin{tabular}{|c|c|c|c|c|c|c|c|}
\hline Año & $\begin{array}{l}\text { Bodas } \\
\text { Totales }\end{array}$ & $\begin{array}{c}\text { Nos Índices } \\
1700-1709 \\
=100\end{array}$ & $\begin{array}{l}\text { Medias } \\
\text { móviles } \\
5 \text { años }\end{array}$ & Año & $\begin{array}{l}\text { Bodas } \\
\text { Totales }\end{array}$ & $\begin{array}{c}\text { Nos Índices } \\
1700-1709 \\
=100\end{array}$ & $\begin{array}{c}\text { Medias } \\
\text { móviles } \\
5 \text { años }\end{array}$ \\
\hline 1722 & 34 & 88 & 36 & 1759 & 27 & 70 & 38 \\
\hline 1723 & 27 & 70 & 35 & 1760 & 34 & 88 & 39 \\
\hline 1724 & 29 & 75 & 35 & 1761 & 46 & 119 & 38 \\
\hline 1725 & 40 & 103 & 35 & 1762 & 47 & 121 & 38 \\
\hline 1726 & 45 & 116 & 37 & 1763 & 34 & 88 & 39 \\
\hline 1727 & 34 & 88 & 38 & 1764 & 31 & 80 & 36 \\
\hline 1728 & 38 & 98 & 37 & 1765 & 37 & 95 & 34 \\
\hline 1729 & 33 & 85 & 36 & 1766 & 31 & 80 & 35 \\
\hline 1730 & 33 & 85 & 37 & 1767 & 37 & 95 & 38 \\
\hline 1731 & 40 & 103 & 38 & 1768 & 41 & 106 & 36 \\
\hline 1732 & 39 & 101 & 37 & 1769 & 43 & 111 & 36 \\
\hline 1733 & 46 & 119 & 36 & 1770 & 27 & 70 & 38 \\
\hline 1734 & 25 & 64 & 35 & 1771 & 33 & 85 & 40 \\
\hline 1735 & 31 & 80 & 35 & 1772 & 47 & 121 & 39 \\
\hline 1736 & 35 & 90 & 34 & 1773 & 49 & 126 & 40 \\
\hline 1737 & 39 & 101 & 37 & 1774 & 37 & 95 & 42 \\
\hline 1738 & 41 & 106 & 38 & 1775 & 35 & 90 & 41 \\
\hline 1739 & 39 & 101 & 37 & 1776 & 41 & 106 & 37 \\
\hline 1740 & 37 & 95 & 43 & 1777 & 41 & 106 & 37 \\
\hline 1741 & 30 & 77 & 47 & 1778 & 33 & 85 & 36 \\
\hline 1742 & 67 & 173 & 47 & 1779 & 33 & 85 & 32 \\
\hline 1743 & 64 & 165 & 48 & 1780 & 30 & 77 & 32 \\
\hline 1744 & 36 & 93 & 50 & 1781 & 25 & 64 & 35 \\
\hline 1745 & 42 & 108 & 47 & 1782 & 37 & 95 & 34 \\
\hline 1746 & 39 & 101 & 42 & 1783 & 49 & 126 & 35 \\
\hline 1747 & 52 & 134 & 44 & 1784 & 28 & 72 & 39 \\
\hline 1748 & 41 & 106 & 43 & 1785 & 35 & 90 & 36 \\
\hline 1749 & 44 & 113 & 45 & 1786 & 44 & 113 & 35 \\
\hline 1750 & 39 & 101 & 43 & 1787 & 24 & 62 & 36 \\
\hline 1751 & 49 & 126 & 43 & 1788 & 42 & 108 & 34 \\
\hline 1752 & 41 & 106 & 40 & 1789 & 36 & 93 & 35 \\
\hline 1753 & 40 & 103 & 40 & 1790 & 26 & 67 & 39 \\
\hline 1754 & 31 & 80 & 38 & 1791 & 49 & 126 & 38 \\
\hline 1755 & 37 & 95 & 38 & 1792 & 40 & 103 & 40 \\
\hline 1756 & 43 & 111 & 38 & 1793 & 38 & 98 & 43 \\
\hline 1757 & 38 & 98 & 38 & 1794 & 49 & 126 & 40 \\
\hline 1758 & 43 & 111 & 37 & 1795 & 39 & 101 & 38 \\
\hline
\end{tabular}


(Continuación)

\begin{tabular}{cccccccc}
\hline Año & $\begin{array}{c}\text { Bodas } \\
\text { Totales }\end{array}$ & $\begin{array}{c}\text { Nos Índices } \\
\mathbf{1 7 0 0 - 1 7 0 9} \\
\mathbf{= 1 0 0}\end{array}$ & $\begin{array}{c}\text { Medias } \\
\text { móviles } \\
\mathbf{5} \text { años }\end{array}$ & $\begin{array}{c}\text { Año } \\
\text { Bodas } \\
\text { Totales }\end{array}$ & $\begin{array}{c}\text { Nos Índices } \\
\mathbf{1 7 0 0 - 1 7 0 9} \\
\mathbf{= 1 0 0}\end{array}$ & $\begin{array}{c}\text { Medias } \\
\text { móviles } \\
\mathbf{5} \text { años }\end{array}$ \\
\hline 1796 & 34 & 88 & 37 & 1806 & 65 & 168 & 50 \\
1797 & 32 & 82 & 33 & 1807 & 63 & 162 & 50 \\
1798 & 29 & 75 & 32 & 1808 & 29 & 75 & 41 \\
1799 & 31 & 80 & 35 & 1809 & 28 & 72 & 30 \\
1800 & 36 & 93 & 35 & 1810 & 20 & 52 & 19 \\
1801 & 48 & 124 & 36 & 1811 & 10 & 26 & 17 \\
1802 & 30 & 77 & 36 & 1812 & 10 & 26 & 18 \\
1803 & 37 & 95 & 42 & 1813 & 19 & 49 & \\
1804 & 30 & 77 & 45 & 1814 & 30 & 77 & \\
1805 & 64 & 165 & 52 & & & & \\
\hline
\end{tabular}

Fuente: Elaboración propia a partir de los libros parroquiales. Se han utilizado todas las parroquias de la ciudad excepto las de San Esteban y Santa María del Poyo por presentar una secuencia incompleta.

Defunciones de adultos en la ciudad de Soria. 1700-1814 (10 parroquias)

\begin{tabular}{ccccccc}
\hline Año & Varones & Mujeres & Totales & $\begin{array}{c}\text { Varones/ } \\
\text { Mujeres }\end{array}$ & $\begin{array}{c}\text { No Índice } \\
\mathbf{1 7 0 0 - 1 7 0 9} \\
\mathbf{1 0 0}\end{array}$ & $\begin{array}{c}\text { Medias } \\
\text { móviles } \\
\mathbf{5} \text { años }\end{array}$ \\
\hline 1700 & 19 & 21 & 40 & 0,90 & 55 & \\
1701 & 25 & 19 & 44 & 1,32 & 61 & \\
1702 & 33 & 24 & 57 & 1,38 & 79 & 50 \\
1703 & 26 & 27 & 53 & 0,96 & 73 & 52 \\
1704 & 26 & 29 & 55 & 0,90 & 76 & 61 \\
1705 & 20 & 30 & 50 & 0,67 & 69 & 85 \\
1706 & 45 & 43 & 88 & 1,05 & 122 & 90 \\
1707 & 100 & 81 & 181 & 1,23 & 250 & 95 \\
1708 & 29 & 47 & 76 & 0,62 & 105 & 110 \\
1709 & 39 & 41 & 80 & 0,95 & 110 & 104 \\
1710 & 53 & 73 & 126 & 0,73 & 174 & 81 \\
1711 & 30 & 29 & 59 & 1,03 & 81 & 81 \\
1712 & 32 & 34 & 66 & 0,94 & 91 & 75 \\
1713 & 31 & 42 & 73 & 0,74 & 101 & 60 \\
1714 & 18 & 33 & 51 & 0,55 & 70 & 56 \\
1715 & 26 & 24 & 50 & 1,08 & 69 & 55 \\
1716 & 17 & 24 & 41 & 0,71 & 57 & 49 \\
\hline
\end{tabular}




\begin{tabular}{|c|c|c|c|c|c|c|}
\hline Año & Varones & Mujeres & Totales & $\begin{array}{l}\text { Varones/ } \\
\text { Mujeres }\end{array}$ & $\begin{array}{c}\text { No Índice } \\
1700-1709 \\
=100\end{array}$ & $\begin{array}{c}\text { Medias } \\
\text { móviles } \\
5 \text { años }\end{array}$ \\
\hline 1717 & 20 & 39 & 59 & 0,51 & 81 & 50 \\
\hline 1718 & 19 & 27 & 46 & 0,70 & 64 & 52 \\
\hline 1719 & 33 & 23 & 56 & 1,43 & 77 & 56 \\
\hline 1720 & 22 & 34 & 56 & 0,65 & 77 & 57 \\
\hline 1721 & 31 & 32 & 63 & 0,97 & 87 & 63 \\
\hline 1722 & 34 & 32 & 66 & 1,06 & 91 & 66 \\
\hline 1723 & 40 & 35 & 75 & 1,14 & 104 & 68 \\
\hline 1724 & 40 & 30 & 70 & 1,33 & 97 & 69 \\
\hline 1725 & 30 & 36 & 66 & 0,83 & 91 & 69 \\
\hline 1726 & 27 & 40 & 67 & 0,68 & 93 & 63 \\
\hline 1727 & 29 & 38 & 67 & 0,76 & 93 & 71 \\
\hline 1728 & 18 & 29 & 47 & 0,62 & 65 & 70 \\
\hline 1729 & 50 & 60 & 109 & 0,83 & 151 & 67 \\
\hline 1730 & 26 & 36 & 62 & 0,72 & 86 & 68 \\
\hline 1731 & 23 & 25 & 48 & 0,92 & 66 & 71 \\
\hline 1732 & 37 & 37 & 74 & 1,00 & 102 & 58 \\
\hline 1733 & 30 & 32 & 62 & 0,94 & 86 & 59 \\
\hline 1734 & 20 & 23 & 43 & 0,87 & 59 & 61 \\
\hline 1735 & 40 & 26 & 66 & 1,54 & 91 & 57 \\
\hline 1736 & 23 & 38 & 61 & 0,61 & 84 & 58 \\
\hline 1737 & 28 & 27 & 55 & 1,04 & 76 & 58 \\
\hline 1738 & 27 & 38 & 65 & 0,71 & 90 & 53 \\
\hline 1739 & 21 & 22 & 43 & 0,95 & 59 & 50 \\
\hline 1740 & 19 & 23 & 42 & 0,83 & 58 & 54 \\
\hline 1741 & 26 & 18 & 44 & 1,44 & 61 & 53 \\
\hline 1742 & 40 & 34 & 74 & 1,18 & 102 & 51 \\
\hline 1743 & 30 & 32 & 62 & 0,94 & 86 & 54 \\
\hline 1744 & 18 & 17 & 35 & 1,06 & 48 & 53 \\
\hline 1745 & 28 & 26 & 54 & 1,08 & 75 & 52 \\
\hline 1746 & 21 & 21 & 42 & 1,00 & 58 & 51 \\
\hline 1747 & 33 & 32 & 65 & 1,03 & 90 & 60 \\
\hline 1748 & 24 & 34 & 58 & 0,71 & 80 & 77 \\
\hline 1749 & 40 & 40 & 80 & 1,00 & 110 & 80 \\
\hline 1750 & 55 & 84 & 139 & 0,65 & 192 & 75 \\
\hline 1751 & 21 & 37 & 58 & 0,57 & 80 & 72 \\
\hline 1752 & 23 & 18 & 41 & 1,28 & 57 & 68 \\
\hline 1753 & 20 & 20 & 40 & 1,00 & 55 & 49 \\
\hline
\end{tabular}


(Continuación)

\begin{tabular}{|c|c|c|c|c|c|c|}
\hline Año & Varones & Mujeres & Totales & $\begin{array}{l}\text { Varones/ } \\
\text { Mujeres }\end{array}$ & $\begin{array}{c}N^{\circ} \text { Índice } \\
1700-1709 \\
=100\end{array}$ & $\begin{array}{c}\text { Medias } \\
\text { móviles } \\
5 \text { años }\end{array}$ \\
\hline 1754 & 31 & 32 & 63 & 0,97 & 87 & 50 \\
\hline 1755 & 15 & 28 & 43 & 0,54 & 59 & 49 \\
\hline 1756 & 22 & 39 & 61 & 0,56 & 84 & 51 \\
\hline 1757 & 22 & 14 & 36 & 1,57 & 50 & 48 \\
\hline 1758 & 23 & 27 & 50 & 0,85 & 69 & 50 \\
\hline 1759 & 14 & 35 & 49 & 0,40 & 68 & 49 \\
\hline 1760 & 26 & 27 & 53 & 0,96 & 73 & 53 \\
\hline 1761 & 27 & 28 & 55 & 0,96 & 76 & 51 \\
\hline 1762 & 28 & 29 & 57 & 0,97 & 79 & 54 \\
\hline 1763 & 19 & 24 & 43 & 0,79 & 59 & 58 \\
\hline 1764 & 29 & 35 & 64 & 0,83 & 88 & 60 \\
\hline 1765 & 32 & 39 & 71 & 0,82 & 98 & 61 \\
\hline 1766 & 38 & 27 & 65 & 1,41 & 90 & 65 \\
\hline 1767 & 37 & 26 & 63 & 1,42 & 87 & 60 \\
\hline 1768 & 30 & 23 & 53 & 1,30 & 73 & 54 \\
\hline 1769 & 22 & 28 & 50 & 0,79 & 69 & 57 \\
\hline 1770 & 26 & 27 & 53 & 0,96 & 73 & 55 \\
\hline 1771 & 33 & 33 & 66 & 1,00 & 91 & 54 \\
\hline 1772 & 26 & 29 & 55 & 0,90 & 76 & 55 \\
\hline 1773 & 27 & 33 & 60 & 0,82 & 83 & 52 \\
\hline 1774 & 20 & 20 & 40 & 1,00 & 55 & 46 \\
\hline 1775 & 23 & 16 & 39 & 1,44 & 54 & 45 \\
\hline 1776 & 19 & 19 & 38 & 1,00 & 52 & 41 \\
\hline 1777 & 18 & 28 & 46 & 0,64 & 64 & 43 \\
\hline 1778 & 27 & 15 & 42 & 1,80 & 58 & 45 \\
\hline 1779 & 29 & 23 & 52 & 1,26 & 72 & 46 \\
\hline 1780 & 19 & 27 & 46 & 0,70 & 64 & 51 \\
\hline 1781 & 23 & 20 & 43 & 1,15 & 59 & 52 \\
\hline 1782 & 38 & 32 & 70 & 1,19 & 97 & 54 \\
\hline 1783 & 23 & 26 & 49 & 0,88 & 68 & 52 \\
\hline 1784 & 31 & 29 & 60 & 1,07 & 83 & 51 \\
\hline 1785 & 19 & 18 & 37 & 1,06 & 51 & 47 \\
\hline 1786 & 23 & 14 & 37 & 1,64 & 51 & 47 \\
\hline 1787 & 23 & 29 & 52 & 0,79 & 72 & 49 \\
\hline 1788 & 23 & 28 & 51 & 0,82 & 70 & 51 \\
\hline 1789 & 27 & 43 & 70 & 0,63 & 97 & 52 \\
\hline 1790 & 24 & 23 & 47 & 1,04 & 65 & 50 \\
\hline
\end{tabular}


(Continuación)

\begin{tabular}{|c|c|c|c|c|c|c|}
\hline Año & Varones & Mujeres & Totales & $\begin{array}{l}\text { Varones/ } \\
\text { Mujeres }\end{array}$ & $\begin{array}{c}N^{\circ} \text { Índice } \\
1700-1709 \\
=100\end{array}$ & $\begin{array}{c}\text { Medias } \\
\text { móviles } \\
5 \text { años }\end{array}$ \\
\hline 1791 & 17 & 23 & 40 & 0,74 & 55 & 47 \\
\hline 1792 & 19 & 25 & 44 & 0,76 & 61 & 42 \\
\hline 1793 & 20 & 15 & 35 & 1,33 & 48 & 40 \\
\hline 1794 & 14 & 28 & 42 & 0,50 & 58 & 40 \\
\hline 1795 & 21 & 19 & 40 & 1,11 & 55 & 40 \\
\hline 1796 & 22 & 17 & 39 & 1,29 & 54 & 44 \\
\hline 1797 & 22 & 22 & 44 & 1,00 & 61 & 45 \\
\hline 1798 & 24 & 30 & 54 & 0,80 & 75 & 47 \\
\hline 1799 & 29 & 20 & 49 & 1,45 & 68 & 47 \\
\hline 1800 & 25 & 24 & 49 & 1,04 & 68 & 48 \\
\hline 1801 & 21 & 20 & 41 & 1,05 & 57 & 55 \\
\hline 1802 & 23 & 23 & 46 & 1,00 & 64 & 78 \\
\hline 1803 & 39 & 52 & 91 & 0,75 & 126 & 79 \\
\hline 1804 & 74 & 87 & 161 & 0,85 & 222 & 82 \\
\hline 1805 & 35 & 21 & 56 & 1,67 & 77 & 83 \\
\hline 1806 & 24 & 30 & 54 & 0,80 & 75 & 74 \\
\hline 1807 & 25 & 29 & 54 & 0,86 & 75 & 51 \\
\hline 1808 & 23 & 20 & 43 & 1,15 & 59 & 49 \\
\hline 1809 & 28 & 19 & 47 & 1,47 & 65 & 45 \\
\hline 1810 & 21 & 24 & 45 & 0,88 & 62 & 44 \\
\hline 1811 & 19 & 16 & 35 & 1,19 & 48 & 45 \\
\hline 1812 & 28 & 21 & 49 & 1,33 & 68 & 44 \\
\hline 1813 & 27 & 20 & 47 & 1,35 & 65 & \\
\hline 1814 & 23 & 21 & 44 & 1,10 & 61 & \\
\hline
\end{tabular}

Fuente: Elaboración propia a partir de los libros parroquiales. Se han utilizado todas las parroquias de la ciudad excepto las de San Esteban y Santa María del Poyo por presentar una secuencia incompleta. 